\author{
KEIO/KYOTO JOINT \\ GLOBAL CENTER OF EXCELLENCE PROGRAM \\ Raising Market Quality-Integrated Design of "Market Infrastructure" \\ KEIO/KYOTO GLOBAL COE DISCUSSION PAPER SERIES
}

DP2010-002

Poverty traps with Local Allocation Tax grants in Japan

Takero Doi*

\begin{abstract}
This paper investigates poverty traps with the Local Allocation Tax (LAT) grants in Japan. The LAT grants, which distributed to local governments by the central government, may be hesitated to make efforts for enhancing regional economic growth, due to the calculation of the LAT grants. We show that the LAT grants give a disincentive to increase their estimated tax revenue and lower regional income by a simple dynamic model. Based on implication of our model, the panel Granger (non-)causality tests are implemented. We find that there are poverty traps due to the LAT grants in Japan.
\end{abstract}

*Takero Doi Keio University

\author{
KEIO/KYOTO JOINT GLOBAL COE PROGRAM \\ Raising Market Quality-Integrated Design of "Market Infrastructure" \\ Graduate School of Economics and Graduate School of Business and Commerce, \\ Keio University \\ 2-15-45 Mita, Minato-ku, Tokyo 108-8345, Japan \\ Institute of Economic Research, \\ Kyoto University \\ Yoshida-honmachi, Sakyo-ku, Kyoto 606-8501, Japan
}




\title{
Poverty traps with Local Allocation Tax grants in Japan*
}

April 2010

\author{
Takero Doi** \\ (Keio University)
}

\begin{abstract}
This paper investigates poverty traps with the Local Allocation Tax (LAT) grants in Japan. The LAT grants, which distributed to local governments by the central government, may be hesitated to make efforts for enhancing regional economic growth, due to the calculation of the LAT grants. We show that the LAT grants give a disincentive to increase their estimated tax revenue and lower regional income by a simple dynamic model. Based on implication of our model, the panel Granger (non-) causality tests are implemented. We find that there are poverty traps due to the LAT grants in Japan.
\end{abstract}

\section{Keywords}

Poverty trap, Local Allocation Tax grants, Regional economic growth, panel Granger (non-) causality tests

JEL classifications

H77, O43, R11

\footnotetext{
* This paper is based on an invited lecture at the Spring Meeting of the Japanese Economic Association held at Kyoto University on 7 June 2009. Financial supports from Grant-in-Aid for Scientific Research (No.19730224) and Keio/Kyoto University Joint Global COE Program 'Raising Market Quality: Integrated Design of Market Infrastructure' are gratefully acknowledged. Valuable comments of two anonymous referees are greatly appreciated. All errors are, of course, my own.

**2-15-45 Mita Minato-ku, Tokyo, 108-8345, Japan. Email: tdoi@econ.keio.ac.jp
} 


\section{Introduction}

Economic and fiscal disparities among regions have received a lot of attention in Japan. The Gini coefficient of real prefectural GDP per capita is increasing since 1996, as shown in Figure 1. Also The Gini coefficient of local tax revenue ${ }^{1}$ per capita by prefecture tends to rise since 1999. Though these inequalities cause concern about the difference of local governments' administrative services between rich and poor regions, Local Allocation Tax (LAT) grants from the central government have a function of interregional income redistribution. The system of the LAT grants is described further in section 2.

The central government distributes the LAT grants to local governments, financed by national taxes collected from people in both urban and rural regions. The LAT grants tends to be allocated more to local governments whose tax revenues are fewer than those whose tax revenues are more.

Local governments whose tax revenues are fewer, however, can receive more LAT grants for any reason. Hence, they may hesitate to make efforts to enlarge their tax base. If they make efforts to enlarge their tax base, their estimated tax revenue will increase. This will reduce their LAT grants receipt. As a result, their efforts to increase their tax revenues are offset by this reduction. In this way, the present system of the LAT grants gives a disincentive to increase their estimated tax revenue.

Many previous studies on the LAT grants pointed out defects of the system. Nagamine (1995) and Doi (1996, 2000) suggest that there are flypaper effects with the LAT grants and it distort resource allocation between private consumption and local expenditures, Hayashi (2000) and Doi and Bessho (2005) find subsidy effects with the LAT grants. It implies that the LAT grants, which are non-matching grants, enhance the specific local expenditures. Akai, Sato, and Yamashita (2005) investigates soft budget problems with the LAT grants. Hayashi (2006) provides a critical survey of previous studies on the LAT grants.

That disincentive may affect regional economic growth. If local governments do not make efforts to increase regional income due to such properties of the LAT grants, regional economic growth may be deteriorated. Though local governments may receive enough revenue sources including the LAT grants and manage public services, growth rate of regional income may continue to be low. The former governor of Tottori prefecture Yoshihiro Katayama intuitively phrased such situations as "poverty traps."2

In this paper, we investigate poverty traps with the LAT grants. First, we explain the system of the LAT grants in section 2. Based on the actual scheme of the LAT grants, we show effects of the LAT grants on economic growth using a simple dynamic model in section3. In section 4, we implement Granger (non-)causality test with panel data in Japan. We

\footnotetext{
1 Including prefectural taxes and municipal taxes.

2 It is based on his presentation at the Decentralization Reform Committee on September 18, 2007.
} 
confirm poverty traps with the LAT grants based on estimation results. Finally concluding remarks follow in section 5 .

\section{System of Local Allocation Tax grants}

The LAT grants are a certain proportion of national taxes that the central government transfers to local governments as a tax source whose purpose is not restricted to balancing local revenue sources between the central government and local governments without prejudicing the independence of local governments. As described in detail in Doi and Ihori (2009), the tax ensures smooth local administration. Local Allocation Tax grants have the following three functions. (a) To redistribute revenue sources between the central government and local governments (to transfer tax revenue from the central government to local governments so that both governments share the function and the gap is filled between public activities and allocation of revenue sources). (b) To ensure revenue sources of local governments (If local governments cannot ensure revenue sources, the central government ensures it instead so that local governments can provide smooth public services). (c) To equalize revenue sources among local governments (The central government adjusts financial resources so that the differences in the financial conditions of local governments are not reflected in the public services).

The central government decides how many LAT grants are allocated to which local governments. Upon allocating ordinary LAT grants, the Standard Financial Revenue (SFR) and the Standard Financial Need (SFN) are calculated for every local government. The SFR is the amount of tax collectable in the usual situation calculated by the central government according to a certain formula for every local government, based on region, size of population and other factors. The details are as shown in Figure 2. The SFN is the amount of expenses necessary for all local governments to carry out independently administrative work at an appropriate and rational level and that the central government calculates using a certain method for every local government, based on region, size of population and other factors. This amount is the aggregate of the amount calculated for every expense item according to the formula, that is, "unit cost" times the mount of "measuring units" times "adjustment coefficient." These terms are explained below, and an outline of this calculation is shown in Table 1.

The unit cost is the amount of revenue sources per unit which is needed for local governments to supply standard public services. The unit cost is computed as the amount of general revenue sources per unit. Extra expenses for public services decided by local governments are excluded.

The measurement unit is used for measuring the estimated cost incurred in each item of public services. A unit that is closely interrelated with the costs concerned is used. Examples are the number of students versus education expenses and population versus social security expenses.

The adjustment coefficient is used for increasing or reducing a unit 
cost to reflect the special environments of each local government. The adjustment coefficients reflect such matters as population density, climate, and geography. It also reflects the "investment mode factor", which is the amount of local government debt incurred in public investments. For example, the more debt a local government has incurred in public investments, the larger the adjustment coefficient of its investment mode factor becomes.

If the SFR is less than the SFN, the difference is called the 'shortfall in revenue source.' The LAT grants are usually granted to local governments with revenue source shortfall (deficit-financed entity). A local government to which ordinary LAT grants is granted is called a "receiving body." The majority of local governments are receiving bodies. The amount of ordinary LAT grants is calculated for every local government based on the difference between the SFN and the SFR. The LAT grants are distributed to each receiving body from the central government. Meanwhile, the ordinary LAT grants is not usually granted to local governments where the mount of the SFR exceeds that of the SFN (surplus-financed entity). A local government to which the ordinary LAT grant is not granted is called a "non receiving body."

\section{A simple model of poverty traps with the LAT grants}

\subsection{Basic framework}

In order to investigate properties of the LAT grants, we focus on a local government in a small open economy. The local government in region $i$ collects local taxes, receives fiscal transfer from the central government, $h_{i, t}$, and issues local government bonds, $b_{i, t}$, to finance it expenditure.

We presume that the local government levy only income taxes at a constant tax rate, $\tau_{L} . \tau_{L}$ is assumed to be constant over time and the same among regions. That is, local tax revenue is equal to $\tau_{L} y_{i, t} \cdot y_{i, t}$ denotes regional income of region $i$ in period $t$. This assumption is valid under the current local tax system in Japan. Tax items and the local tax rates are specified in the Local Tax Law, which is a national law. Moreover, local governments impose local taxes at their own discretion and do not substantially exercise right to set local tax rates.

We assume that the local government has two kinds of expenditure. The one is welfare-improving (but unproductive) government consumption, $g_{i, t}$. The other is productive government investment, $x_{i, t}$. This investment can increase production in this region in the next period. Note that this government investment may not be equated with public fixed capital formation or public works in local budget, since inefficient investment and investment without increasing future regional production may be included in them. We assume the following intertemporal utility function of the local government

$$
U_{i}=\sum_{t=1}^{\infty} \frac{u_{i}\left(g_{i, t}\right)}{(1+\rho)^{t}} \quad \rho>0
$$


where $\rho$ is the subjective discount rate. ${ }^{3}$

The budget constraint of the local government is expressed as

$$
b_{i, t}=g_{i, t}+x_{i, t}+(1+r) b_{i, t-1}-\tau_{L} y_{i, t}-h_{i, t}
$$

where $r$ is the interest rate, given exogenously, as the economy is small open. $b_{i, t}$ denotes the outstanding local government debt of region $i$ at the end of period $t$. The initial level of local government debt sets $b_{i, 0}$, given exogenously.

We employ a Solow-Swan growth model. Investment rate in region $i$ is assumed to be given exogenously. It is a constant over time, $s_{i}>0$. Production function in this region is expressed as

$$
\begin{aligned}
& y_{i, t}=f_{i}\left(k_{i, t-1}, x_{i, t-1}\right) \\
& \text { where } \frac{\partial y_{i, t}}{\partial k_{i, t-1}}>0, \frac{\partial^{2} y_{i, t}}{\partial k_{i, t-1}{ }^{2}}<0, \frac{\partial y_{i, t}}{\partial x_{i, t-1}}>0, \frac{\partial^{2} y_{i, t}}{\partial x_{i, t-1}{ }^{2}}<0, \frac{\partial^{2} y_{i, t}}{\partial k_{i, t-1} \partial x_{i, t-1}}>0 .
\end{aligned}
$$

$k_{i, t-1}$ is capital equipped by private firms in region $i$ at the end of period $t-1$ (that is, at the beginning of period $t$ ). The initial level of private capital and government investment set $x_{i, 0}$ and $k_{i, 0}$, given exogenously, respectively. This production function is assumed to satisfy the Inada condition. The capital depreciates at the constant rate $\delta>0$. On the other hand, the government investment fully depreciates in the next period. Thus

$$
k_{i, t}=(1-\delta) k_{i, t-1}+s_{i}\left(1-\tau_{L}-\tau_{C}\right) y_{i, t}
$$

where $\tau_{C}$ denotes national tax rate for fiscal transfer from the central government. That is,

$$
\sum_{i=1}^{N} \tau_{C} y_{i, t}=\sum_{i=1}^{N} h_{i, t} .
$$

In order to focus on behaviors of local government, we do not investigate behaviors (or the objective function) of the central government in this paper. Policies of the central government are assumed to be exogenously given. Now, $\tau \equiv \tau_{L}+\tau_{C}$.

We suppose the local government is myopic in the sense that it does not take into account interregional migration of residents and interregional capital flows. ${ }^{4}$

First, we examine effects of lump-sum transfer from the central government as the benchmark case. Lump-sum transfer has no substitution effects. The local government $i$ maximizes the utility function (1) subject to the budget constraint (2) and (3). First order conditions of this optimization problem are as follows.

\footnotetext{
3 We can interpret this function as the objective function of the local government. Or else, we can interprets it as the utility function of the representative resident in region $i$. In this case, this function is assumed to be additively separable with respect to his/her utilities from welfare-improving government consumption and private goods.

4 Perfectly free migration of residents makes the utility of residents be equalized among regions. Also perfectly free interregional capital flows makes return of capital be equalized among regions. However, we presume the local government cannot take into account these conditions in maximizing its utility.
} 


$$
\begin{aligned}
& \frac{u_{i}^{\prime}\left(g_{i, t}\right)}{(1+\rho)^{t}}-\lambda_{i, t}=0 \\
& -\lambda_{i, t}+\lambda_{i, t+1} \tau_{L} \frac{\partial y_{i, t+1}}{\partial x_{i, t}}=0 \\
& -\lambda_{i, t-1}(1+r)+\lambda_{i, t}=0
\end{aligned}
$$

And the following transversality condition is satisfied.

$$
\lim _{t \rightarrow \infty} \lambda_{i, t} \frac{b_{i, t}}{(1+\rho)^{t}}=0
$$

Hence,

$$
\begin{aligned}
& \frac{u_{i}^{\prime}\left(g_{i, t}\right)}{u_{i}^{\prime}\left(g_{i, t-1}\right)}=\frac{1+\rho}{1+r} \\
& \frac{\partial y_{i, t}}{\partial x_{i, t-1}}=\frac{1+r}{\tau_{L}}
\end{aligned}
$$

The above optimality conditions (7), (8), the budget constraint of local government (2) and the low of motion for capital (4) determine resource allocation as the benchmark case. Condition (7) governs intertemporal allocation of government consumption. Condition (8) is the efficiency criterion of government investment.

\subsection{Effects of the Standard Financial Revenue in the LAT grants}

Second, we investigate effects of the Standard Financial Revenue (SFR) in the LAT grants. As explained in section 2, the amount of the (ordinary) LAT grant is calculated for each local government based on the difference between the SFN and the SFR. Thus, we can express as follows

$$
h_{i, t}=\eta_{t} g_{i, t}-\theta \tau_{L} y_{i, t} \quad 1>\eta_{t}>0,1>\theta>0
$$

This $h_{i, t}$ is determined to satisfy the budget constraint (5) through adjusting the coefficient of government consumption, $\eta_{t}$. $\eta_{t}$ may vary over time. $\eta_{t} g_{i, t}$ implies the SFN in this case. According to the current system of LAT grants, the SFN for government investment should be included. In this section, however, it is excluded for simplicity. We include it in the SFN in the next section. Moreover, $\theta \tau_{L} y_{i, t}$ means the SFR. As mentioned above, $\theta$ is $75 \%$ in the current system. $\theta$ is assumed to be constant over time, since it is actually unchanged over time under the current system.

$$
\begin{aligned}
& \text { Substituting (9) into (2), } \\
& b_{i, t}=\left(1-\eta_{t}\right) g_{i, t}+x_{i, t}+(1+r) b_{i, t-1}-(1-\theta) \tau_{L} y_{i, t}
\end{aligned}
$$

The local government $i$ maximizes the utility function (1) subject to the budget constraint (2') and (3). First order conditions of this optimization problem are as follows.

$$
\begin{aligned}
& \frac{u_{i}^{\prime}\left(g_{i, t}\right)}{(1+\rho)^{t}}-\left(1-\eta_{t}\right) \lambda_{i, t}=0 \\
& -\lambda_{i, t}+\lambda_{i, t+1}(1-\theta) \tau_{L} \frac{\partial y_{i, t+1}}{\partial x_{i, t}}=0
\end{aligned}
$$




$$
\lambda_{i, t}-\lambda_{i, t+1}(1+r)=0
$$

And the transversality condition (6) is satisfied. Hence,

$$
\begin{aligned}
& \frac{u_{i}^{\prime}\left(g_{i, t}\right)}{u_{i}^{\prime}\left(g_{i, t-1}\right)}=\frac{(1+\rho)\left(1-\eta_{t}\right)}{(1+r)\left(1-\eta_{t-1}\right)} \\
& \frac{\partial y_{i, t}}{\partial x_{i, t-1}}=\frac{1+r}{(1-\theta) \tau_{L}}>\frac{1+r}{\tau_{L}}>0
\end{aligned}
$$

The condition for government investment is distorted by the LAT grants. In particular, this distortion is due to the SFR. From the property of the production function, condition (11) implies the government investment $x_{t}$ decreases compared with the benchmark case. It means a decrease in regional production.

Furthermore, we can explain poverty traps due to the LAT grants. The production function is assumed to be the following AK function. That is,

$$
y_{i, t}=A_{i}\left(x_{i, t-1}\right) k_{i, t-1}
$$

where $A_{i}\left(x_{t-1}\right)$ is a function of $x_{i, t-1}$ with $A_{i}{ }^{\prime}\left(x_{i, t-1}\right)>0$, and $A_{i}{ }^{\prime \prime}\left(x_{i, t-1}\right)<0$. $^{5}$ Thus,

$$
k_{i, t}=(1-\delta) k_{i, t-1}+s_{i}(1-\tau) A_{i}\left(x_{i, t-1}\right) k_{i, t-1}
$$

From (4'), the growth rate of capital is represented as

$$
\frac{k_{i, t}}{k_{i, t-1}}=1-\delta+s_{i}(1-\tau) A_{i}\left(x_{i, t-1}\right)
$$

Under such a formula of the LAT grants, the government investment in this case decreases compared with the benchmark case. That is, $A_{i}\left(x_{i, t-1}\right)$ decreases. The growth rate of $k_{i, t}$ may decrease due to the LAT grants. If $1-\delta+s_{i}(1-\tau) A_{i}\left(x_{i, t-1}\right)<1, k_{i, t}<k_{i, t-1}$. For example, when $\delta=0.05, s_{i}=0.1, \tau=$ $0.3, A_{i}\left(x_{i, t-1}\right)=0.6,1-\delta+s_{i}(1-\tau) A_{i}\left(x_{i, t-1}\right)<1$.

Also under this specification, (11) is replaced by

$$
\frac{\partial y_{i, t}}{\partial x_{i, t-1}}=A_{i}^{\prime}\left(x_{i, t-1}\right) k_{i, t-1}=\frac{1+r}{(1-\theta) \tau_{L}}
$$

If $k_{i, t}<k_{i, t-1}, \quad A_{i}^{\prime}\left(x_{i, t}\right)>A_{i}^{\prime}\left(x_{i, t-1}\right)$ from (11'), because $A_{i}^{\prime}\left(x_{i, t}\right) k_{i, t}=A_{i}^{\prime}\left(x_{i, t-1}\right) k_{i, t-1}$. Hence $x_{i, t}<x_{i, t-1}$ under this specification. ${ }^{6}$ It implies $y_{i, t}<y_{i, t-1}$.

In this situation, the steady state of regional income is zero, as shown in Figure 3. That is a kind of poverty traps. It is similar to the kleptocratic poverty trap, introduced by Azariadis (2006). Azariadis and Stachurski (2005) define a poverty trap as any self-reinforcing mechanism which causes poverty to persist. Poverty traps defined above are consistent with this definition.

5 As shown in Appendix, the analytical results would be qualitatively the same even if we consider more general form of the production function.

6 Incidentally, from (4') and (11'), the series of $\left\{x_{i, t}\right\}$ is determined by $A^{\prime}\left(x_{i, 1}\right)=\frac{1+r}{(1+\theta) \tau_{L} k_{i, 0}\left\{1-\delta+s_{i}(1-\tau) A_{i}\left(x_{i, 0}\right)\right\}}, \cdots, \quad A^{\prime}\left(x_{i, t}\right)=\frac{1+r}{(1+\theta) \tau_{L} k_{i, 0} \prod_{j=1}^{t-1}\left\{1-\delta+s_{i}(1-\tau) A_{i}\left(x_{i, j}\right)\right\}}$. 
Consequently, the LAT grants may decrease productive government investment and lower growth rates of capital and regional income. It is a cause of poverty traps.

\subsection{Effects of the Standard Financial Need in the LAT grants}

Finally, we investigate effects of the Standard Financial Need (SFN) in the LAT grants. In addition to (9), compensation for government investment is included in the SFN. Thus, we can express as follows

$$
\begin{aligned}
& h_{i, t}=\eta_{t} g_{i, t}+\omega_{t} \alpha_{i, t-1} x_{i, t-1}-\theta \tau_{L} y_{t} \\
& \quad \text { where } 1>\eta_{t}>0,1>\theta>0,1>\omega_{t}>0,1<\alpha_{i, t-1}
\end{aligned}
$$

$\omega_{t} \alpha_{i, t-1} x_{i, t-1}$ reflects the "investment mode factor," as described in section 2. $\omega_{t}$ denotes the coefficient of the investment mode factor. $\alpha_{i, t-1}$ means a coefficient which implies gap between productive public investment and unproductive one. More specifically, $\alpha_{i, t-1} x_{i, t-1}$ is the actual expenditure for public investment, but just $x_{i, t-1}$ is productive public investment, which increases regional production, and $\left(\alpha_{i, t-1}-1\right) x_{i, t-1}$ is unproductive public investment, which does not increase regional production, in region $i$ in period $t-1$. The bigger $\alpha_{i, t-1}$ is, the larger the fraction of unproductive public investment is. Such situation that $\alpha_{i, t}$ in the entire period equals one is the same as one in section 3.1 and 3.2 .

This $h_{i, t}$ in (9) satisfies the budget constraint (5). $\eta_{t}$ and $\omega_{t}$ may vary over time through decision-making process of the LAT grants. Also $\alpha_{i, t}$ may vary over time and across regions. We suppose that $\alpha_{i, t}$ is exogenously given for the local governments.

Substituting (9') into (2),

$$
b_{i, t}=\left(1-\eta_{t}\right) g_{i, t}+\alpha_{i, t} x_{i, t}-\omega_{t} \alpha_{i, t-1} x_{i, t-1}+(1+r) b_{i, t-1}-(1-\theta) \tau_{L} y_{i, t}
$$

The local government maximizes the utility function (1) subject to the budget constraint (2") and (3). First order conditions of this optimization problem are as follows.

$$
\begin{aligned}
& \frac{u_{i}^{\prime}\left(g_{i, t}\right)}{(1+\rho)^{t}}-\left(1-\eta_{t}\right) \lambda_{i, t}=0 \\
& -\lambda_{i, t} \alpha_{i, t}+\lambda_{i, t+1}\left\{(1-\theta) \tau_{L} \frac{\partial y_{i, t+1}}{\partial x_{i, t}}+\omega_{t+1} \alpha_{i, t+1}\right\}=0 \\
& \lambda_{i, t}-\lambda_{i, t+1}(1+r)=0
\end{aligned}
$$

And the transversality condition (6) is satisfied. Hence,

$$
\begin{aligned}
& \frac{u_{i}^{\prime}\left(g_{i, t}\right)}{u_{i}^{\prime}\left(g_{i, t-1}\right)}=\frac{(1+\rho)\left(1-\eta_{t}\right)}{(1+r)\left(1-\eta_{t-1}\right)} \\
& \frac{\partial y_{i, t}}{\partial x_{i, t-1}}=\frac{(1+r) \alpha_{i, t-1}-\omega_{t} \alpha_{i, t}}{(1-\theta) \tau_{L}}
\end{aligned}
$$

Whether the above partial differential coefficient in (12) is more than $(1+r) / \tau_{L}$ is not trivial. The parameter $\omega_{t}$ has a subsidy effect for productive 
government investment. If $\omega_{t} \alpha_{i, t}>(1+r)\left(\theta+\alpha_{i, t-1}-1\right), \frac{(1+r) \alpha_{i, t-1}-\omega_{t} \alpha_{i, t}}{(1-\theta) \tau_{L}}<\frac{1+r}{\tau_{L}}$.

It implies that productive government investment is enhanced by the LAT grants under this condition. In this case, growth rate of capital and regional income is higher than that in the benchmark case. For example, when $\theta=$ $0.75, r=0.02, \omega_{t}=0.8, \tau_{L}=0.1$, and $\alpha_{i, t-1}=\alpha_{i, t}=1.1$ in any period $t, \omega_{t} \alpha_{i, t}>$ $(1+r)\left(\theta+\alpha_{i, t-1}-1\right)$. On the other hand, when all parameters are the same value excluding $\alpha_{i, j}>1.16$ in any period $j \geq t-1, \omega_{t} \alpha_{i, t}<(1+r)\left(\theta+\alpha_{i, t-1}-1\right)$. That is, when unproductive public investment increases, growth rate of capital and regional income cannot be higher by the LAT grants than that in the benchmark case. In such situation, the LAT grants may induce poverty traps though investment mode factor is reflected.

In the next section, we confirm whether the LAT grants enhance or deteriorate regional economic growth by using panel data on the Japanese regional economy and local public finance.

\section{Empirical analyses of poverty traps}

\subsection{Panel Granger (non-)causality test}

We can recognize poverty traps described in section 3 as causality from receipt of the LAT grants to regional economic growth. However, prefectural GDP data is continuously available only from 1990. It is too short time span to estimate vector autoregression or vector error correction models by prefecture. So we employ panel Granger (non-)causality tests.

In an early stage, Holtz-Eakin, Newey and Rosen (1988) proposed the following linear model for a panel causality test

$$
\begin{aligned}
Y_{i, t}=\sum_{j=1}^{J} \gamma^{j} Y_{i, t-j}+\sum_{j=1}^{J} \beta^{j} X_{i, t-j}+\mu_{i}+\varepsilon_{i, t} \\
\quad \text { where } i=1,2, \ldots, N . t=1,2, \ldots, T . \varepsilon_{i, t} \text { are i.i.d. with } \mathrm{E}\left(\varepsilon_{i, t}\right)=0 \\
\mathrm{E}\left(\varepsilon_{i, t}^{2}\right)=\sigma_{\varepsilon, t}^{2}
\end{aligned}
$$

This specification is assumed to be the same parameters, $\beta^{j}$ and $\gamma^{j}$, among individuals.

More generally, we can make these parameters different among individuals. Thus

$$
Y_{i, t}=\sum_{j=1}^{J} \gamma_{i}^{j} Y_{i, t-j}+\sum_{j=1}^{J} \beta_{i}^{j} X_{i, t-j}+\mu_{i}+\varepsilon_{i, t}
$$

Hurlin and Venet (2004), and Hurlin (2005, 2008) adopted the above linear model with fixed coefficients and a Wald test for the Granger (non-)causality hypothesis in heterogeneous panel data. Methodology of these tests is used by Im, Pesaran, and Shin (2003) to test the unit root hypothesis. Also these causality tests are applied in Peltrault and Venet (2005), Bhaduri and Durai (2006), and Suliman (2008). ${ }^{7}$

\footnotetext{
7 Hurlin and Venet (2001) proposed an F test for panel causality test, though it is similar to Hurlin and Venet (2004), and Hurlin (2005, 2008). This test is applied in
} 
Hurlin and Venet (2004), and Hurlin (2005, 2008) set the following null hypothesis in (13),

$$
\begin{aligned}
\mathrm{H}_{0}: \boldsymbol{\beta}_{i}= & 0 \quad \forall i=1,2, \ldots, N \\
& \text { where } \boldsymbol{\beta}_{i}=\left(\beta_{i}^{1}, \beta_{i}^{2}, \cdots, \beta_{i}^{J}\right)^{\prime}
\end{aligned}
$$

This is the homogenous non-causality (HNC) hypothesis. The alternative hypothesis is

$$
\begin{aligned}
\mathrm{H}_{1}: \boldsymbol{\beta}_{i}=0 & \forall i=1,2, \ldots, N_{1} \quad\left(N_{1}<N\right) \\
\boldsymbol{\beta}_{i} \neq 0 & \forall i=N_{1}+1, N_{1}+2, \ldots, N
\end{aligned}
$$

where $N_{1}$ is unknown but satisfies the condition $0 \leq N_{1} / N<1$ : The fraction $N_{1} / N$ is necessarily inferior to one, since if $N_{1}=N$ there is no causality for all the individual of the panel, and then we get the null hypothesis HNC. Hurlin and Venet (2004), and Hurlin (2005, 2008) proposed using the average of individual Wald statistics to test the HNC hypothesis for individuals, such that

$$
W_{N, T}^{H n c}=\frac{1}{N} \sum_{i=1}^{N} W_{i, T}
$$

where $W_{i, T}$ denotes the individual Wald statistics for the $i$ th cross section unit associated to the individual test $\mathrm{H}_{0}: \beta_{i}=0$.

In a large $T$ sample,

$$
\sqrt{\frac{N}{2 J}}\left(W_{N, T}^{H n c}-J\right) \underset{r, N \rightarrow \infty}{\longrightarrow} N(0,1)
$$

However, we have a small $T$ sample. For a fixed $T>5+2 J$, Hurlin and Venet $(2004)$, and Hurlin $(2005,2008)$ proposed to compute the following approximated standardized statistic

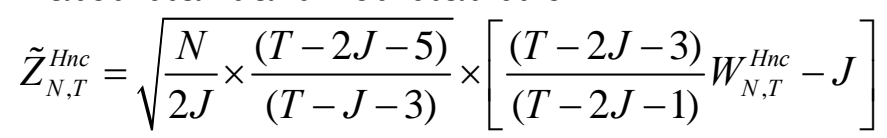

This standardized average statistic $\tilde{Z}_{N, T}^{H n c}$ converges in distribution as follows

$$
\tilde{Z}_{N, T}^{H n c} \underset{N \rightarrow \infty}{\longrightarrow} N(0,1)
$$

Hurlin (2008) shows power of this panel Granger non-causality test based on Monte Carlo simulations. It implies that the above statistics provide very good small sample properties.

Therefore, we use equation (13) and statistic $\tilde{Z}_{N, T}^{H n c}$ to implement panel non-causality test on regional economic growth and the LAT grants.

\subsection{Prefectural data}

Prefectural GDP data based on System of National Accounts 1993 (93SNA) is available from 1990. This data is taken from Cabinet Office "Annual Report on Prefectural Accounts." Also GDP deflator is taken from it as a price index. Data of the LAT grants is taken from Ministry of Internal Affairs and Communications "Annual Statistical Report on Local

Hansen and Rand (2006), Hood, Kidd, and Morris (2008), Erdila and Yetkiner (2009), and He and Zhang (2010). 
Government Finance." Population by prefecture is taken from Ministry of Internal Affairs and Communications "Basic Resident Registers." We set sample period is from fiscal 1990 to 2006.

All variables are expressed in per capita real term basis because there is a significant difference in population among prefectures. We use real GDP per capita (GDP), per capita real LAT grants received by just prefecture (LATGP), and per capita real LAT grants received by prefecture and municipalities (LATGT).

Tokyo, Kanagawa, Aichi, and Osaka prefectures have been non-receiving bodies of the LAT grants. Since we focus on receiving bodies of the LAT grants, we exclude these four prefectures. Thus we have 43 prefectures in our sample.

\subsection{Test results}

First, we implement a unit root test proposed by Im, Pesaran, and Shin (2003). The result is reported in Table 2. This test concludes to the rejection of the non stationarity hypothesis for all three variables.

Before the Granger non-causality tests, we estimate equations based on (13) and identify their lag length.

$$
\begin{aligned}
& G D P_{i, t}=\sum_{j=1}^{J} \alpha_{i}^{j} G D P_{i, t-j}+\sum_{j=1}^{J} \beta_{i}^{j} L A T G X_{i, t-j}+\mu_{i}^{G D P}+\varepsilon_{i, t}^{G D P} \\
& L A T G X_{i, t}=\sum_{j=1}^{J} \gamma_{i}^{j} G D P_{i, t-j}+\sum_{j=1}^{J} \zeta_{i}^{j} L A T G X_{i, t-j}+\mu_{i}^{L A T G X}+\varepsilon_{i, t}^{L A T G X}
\end{aligned}
$$

where LATGX means LATGP or LATGT

As determined by the Schwarz criterion, shown in Table 3, lag length equals one.

Based on these equations with $J=1$, the panel Granger non-causality test proposed by Hurlin and Venet (2004), and Hurlin (2005, 2008) is implemented. The test statistics and their p-values are reported in Table 4. From these results, the null hypothesis in all regressions is rejected at a 5 percent significant level. We find Granger causality from real prefectural GDP per capita to per capita real LAT grants, and vice versa, in some prefectures.

Moreover, we show estimation results in Table 5.8 In (14), the LAT grants in last year (LATGP) are negatively correlated with prefectural GDP in most prefectures. Also these estimated coefficients $\left(\beta_{i}{ }^{1}\right)$ are significant at a 5 percent significant level in some prefectures in Tables 5-1 (the LATGP case) and 5-3 (the LATGT case). Especially, prefectures in urban area and their neighborhood have significantly negative coefficients $\left(\beta_{i}^{1}\right)$; For example, Miyagi $(i=5)$, Saitama (11), Chiba (12), Kyoto (26), Hyogo (28), Nara (29), Okayama (33), Hiroshima (34), Fukuoka (40), Saga (41), and Nagasaki (42) in both cases. In these prefectures, Miyagi, Saitama, Chiba, Kyoto, Hyogo, Hiroshima, and Fukuoka have government-designated cities, which are the

\footnotetext{
8 In Table 5, estimated coefficients of fixed effect (i.e. prefecture dummies) are omitted to report.
} 
largest cities in Japan. ${ }^{9}$ In such prefectures, it seems that an increase in the LAT grants significantly reduces real prefectural GDP.

Incidentally, we also estimate equations (14) and (15) in all prefectures including Tokyo, Kanagawa, Aichi, and Osaka. In these four prefectures, there are municipalities which receive the LAT grants, though prefectural governments do not receive the LAT grants. These results are shown in Tables 5-5 and 5-6. These are almost the same as results in Tables 5-3 and 5-4.

Based on estimation results in Tables 5-3 and 5-4, we estimate impulse response functions in 43 prefectures. We investigate the estimated impulse responses to a one-standard-deviation shock of LATGT $(0.01158$, shown in Table 5-4). Accumulated impulse responses of prefectural GDP and LATGT to one standard deviation shocks of LATGT are shown in Figure 4. Each gray line in this figure implies accumulated impulse response of each prefecture. The results suggest that the shock caused by an increase in the LAT grants (per capita in real term) leads to a decrease in real GDP per capita in almost all prefectures. In other words, an increase in the LAT grants (per capita in real term) reduces real prefectural GDP per capita in almost all prefectures. In Figure 4, in just 3 prefectures, which have positive but insignificant estimated $\beta_{i}{ }^{1}$, their prefectural GDPs increase in this situation.

These means that an increase in the LAT grants cause a decrease in prefectural GDP. That indicates phenomenon of poverty traps due to the LAT grants.

\section{Concluding remarks}

We have examined poverty traps with the LAT grants in Japan. As mentioned above, the LAT grants may be hesitated to make efforts for enhancing regional economic growth. We show that the LAT grants give a disincentive to increase their estimated tax revenue and lower regional income by a theoretical model.

Based on implication of our dynamic model, the panel Granger (non-)causality tests are implemented. The heterogeneous autoregressive model with fixed coefficients and a Wald test for the Granger (non-)causality hypothesis proposed by Hurlin and Venet (2004), and Hurlin (2005, 2008) is employed as causality tests in this paper. As our results, we find that there are poverty traps due to the LAT grants.

On the other hand, Nishikawa and Yokoyama (2004) examine another poverty trap with the LAT grants. They describe that this trap causes negligence for tax collection of local governments. If local governments that receive lots of LAT grants slack their efforts to collect local taxes, their Standard Financial Revenue in calculation of the LAT grants

\footnotetext{
9 Four eliminated prefectures in these estimation, Tokyo, Kanagawa, Aichi, and Osaka, also have government-designated cities or special wards, which are administrative divisions in the central area of Tokyo.
} 
becomes lower and their receipt of the LAT grants becomes more. However, they find no evidence of this type of poverty traps.

Despite this, results in this paper are not inconsistent with their study. Nishikawa and Yokoyama (2004) focuses on incentives for tax collection of local government, but does not define poverty traps as being related to regional income. Poverty traps defined in this paper disincentive effects with the LAT grants to regional income or regional economic growth, though we do not deal with such incentives. Poverty traps defined in this paper is conceptually close to the definition of Azariadis and Stachurski (2005)

Poverty traps shown in this paper cause the formula of the LAT grants. In particular, the amount of the ordinary LAT grant is calculated for each local government based on the difference between the SFN and the SFR. This calculation is a significant fault of the LAT grants in this sense. In future decentralization reform in Japan, the calculation of the LAT grants should be revised. For example, the central government should reorganize the current intergovernmental transfers, the LAT grants and national government disbursement, as Doi and Ihori (2009) proposed. To ensure revenue sources of local governments, the central government should grant specific fixed-amount subsidies to national-minimum service providers (such as local governments). If subsidies are granted in this manner, there is no need to employ the gap-filling approach seen in the current LAT grant scheme. Moreover, the fiscal equalization system may be established to equalize revenue sources among local governments, if needed. These are one way of break out of poverty traps in the Japanese rural regions.

\section{Appendix}

In the case of a more general form of production function, we can describe an analysis in section 3.2 as follows. Using the more general form of production function (3), equation (4') is rewritten as

$$
k_{i, t}=(1-\delta) k_{i, t-1}+s_{i}(1-\tau) f_{i}\left(k_{i, t-1}, x_{i, t-1}\right)
$$

From (4"), the growth rate of capital is represented as

$$
\frac{k_{i, t}}{k_{i, t-1}}=1-\delta+s_{i}(1-\tau) \frac{f_{i}\left(k_{i, t-1}, x_{i, t-1}\right)}{k_{i, t-1}}
$$

If $1-\delta+s_{i}(1-\tau) \frac{f_{i}\left(k_{i, t-1}, x_{i, t-1}\right)}{k_{i, t-1}}<1, k_{i, t}<k_{i, t-1}$. Under such a formula of the LAT grants, (11') is replaced by

$$
\frac{\partial y_{i, t}}{\partial x_{i, t-1}}=\frac{\partial f_{i}\left(k_{i, t-1}, x_{i, t-1}\right)}{\partial x_{i, t-1}}=\frac{1+r}{(1-\theta) \tau_{L}}
$$

It implies that $\frac{\partial f_{i}\left(k_{i, t-1}, x_{i, t-1}\right)}{\partial x_{i, t-1}}$ is constant over time in more general setting. 
In (3), we have assumed that $\frac{\partial^{2} y_{i, t}}{\partial k_{i, t-1} \partial x_{i, t-1}}>0$. Therefore, if $k_{i, t}<k_{i, t-1}$, $\frac{\partial f_{i}\left(k_{i, t}, x\right)}{\partial x}<\frac{\partial f_{i}\left(k_{i, t-1}, x\right)}{\partial x}$ in the same value of $x$. Since $\frac{\partial f_{i}\left(k_{i, t-1}, x_{i, t-1}\right)}{\partial x_{i, t-1}}$ is constant over time, however, $x_{i, t}$ satisfies $x_{i, t}<x_{i, t-1}$. Such situation that $k_{i, t}<k_{i, t-1}$ and $x_{i, t}<x_{i, t-1}$ implies $y_{i, t}<y_{i, t-1}$.

As a result, the analytical results in section 3.2 would be qualitatively the same in a more general form of the production function.

\section{Reference}

Akai, N, M. Sato, and K. Yamashita, 2003, Economics of Local Allocation Tax Grants, Yuhikaku Inc. (in Japanese)

Azariadis, C., 2006, The theory of poverty traps: What have we learned?, in Bowles, S., S.N. Durlauf, and K. Hoff eds., Poverty Traps, Princeton University Press, pp.17-40.

Azariadis, C. and J. Stachurski, 2005, Poverty Traps, in P. Aghion and S. Durlauf, eds., Handbook of Economic Growth vol.1A, pp.295-384.

Bhaduri, S.N., and S.R.S. Durai, 2006, Empirical relationship between the dividend and investment decision: Do emerging market firms behave differently?, Applied Financial Economics Letters vol.2, pp.155-158

Doi, T., 1996, Flypaper effect in Japanese urban expenditure, Financial Review vol.40, pp.95-119. (in Japanese)

Doi, T., 2000, Political Economy of the Japanese Local Finance, Toyo Keizai Inc. (in Japanese).

Doi, T. and S. Bessho, 2005, Local borrowing subsidized through Local Allocation Tax grants: Does it increase capital spending?, Japan Center for Economic Research Economic Journal vol.51, pp.33-58. (in Japanese).

Doi, T. and T. Ihori, 2009, The Public Sector in Japan, Edward Elgar Publishing.

Erdila, E., and I.H. Yetkiner, 2009, The Granger-causality between health care expenditure and output: A panel data approach, Applied Economics vol.41, pp.511-518

Maddisona, D., and K. Rehdanz, 2008, Carbon emissions and economic growth: Homogeneous causality in heterogeneous panels, Kiel Working Papers No.1437, Kiel Institute for the World Economy.

Hansen, H. and J. Rand, 2006, On the causal links between FDI and growth in developing countries, World Economy vol.29, pp.21-41.

Hayashi, M., 2000, Distortionary effects of seemingly lump-sum intergenerational transfers in Japan: A note, Economic Research (Meijigakuin University), vol.118, pp.63-71.

Hayashi, M., 2006, Economic studies of the Local Allocation Tax in Japan: A critical survey, Journal of Economic Policy Studies vol.3 no.2, pp.6-24. 
(in Japanese)

He, D. and W. Zhang, 2010, How dependent is the Chinese economy on exports and in what sense has its growth been export-led?, Journal of Asian Economics vol.21 no.1, pp.87-104.

Holtz-Eakin, D., W. Newey, and Rosen, H., 1988, Estimating vector autoregressions with panel data, Econometrica vol.56, pp.1371-95.

Hood III, M.V., Q. Kidd, and I.L. Morris, 2008, Two sides of the same coin? Employing Granger causality tests in a time series cross-section framework, Political Analysis vol.16, pp.324-344.

Hurlin, C., and B. Venet, 2001, Granger causality tests in panel data models with fixed coefficients. Working Paper, Department of Economics, University Paris IX Dauphine.

Hurlin, C and B. Venet, 2004, Financial development and growth: a re-examination using a panel Granger causality test, Document de recherché LEO 2004-05, Université d'Orléans.

Hurlin, C., 2005, Un test simple de l'hypothèse de non-causalité dans un modèle de panel hétérogène ( $\mathrm{A}$ simple test of the no-causality hypothesis in a heterogeneous panel model), Revue Economique vol.56, pp. $1-11$

Hurlin, C., 2008, Testing for Granger non-causality in heterogeneous panels, Working Papers No.halshs-00224434_v1, Hyper Article en Ligne, Sciences de l'Homme et de la Société.

http://halshs.archives-ouvertes.fr/docs/00/22/44/34/PDF/Causality_WP. pdf

Im, K. S., M. H. Pesaran, and Y. Shin, 2003, Testing for unit roots in heterogeneous panels, Journal of Econometrics vol.115, pp.53-74.

Nagamine, 1995, Japanese local finance and the "institutionalized" flypaper effect, Public Finance vol.50, pp.420-441.

Nishikawa, M. and A. Yokoyama, 2004, Incentives for tax collection of local governments, Japan Center for Economic Research Economic Journal vol.55, pp.165-179. (in Japanese)

Peltrault, F. and B. Venet, 2005, Intra-industry trade and economic distance: Causality tests using panel data, mimeo.

Suliman, O., 2008, Do capital inflows cause currency black markets in MENA?: Causality tests for heterogeneous panels, Economic Research Forum Working Paper 381. 
Figure 1

\section{Gini Coefficients}

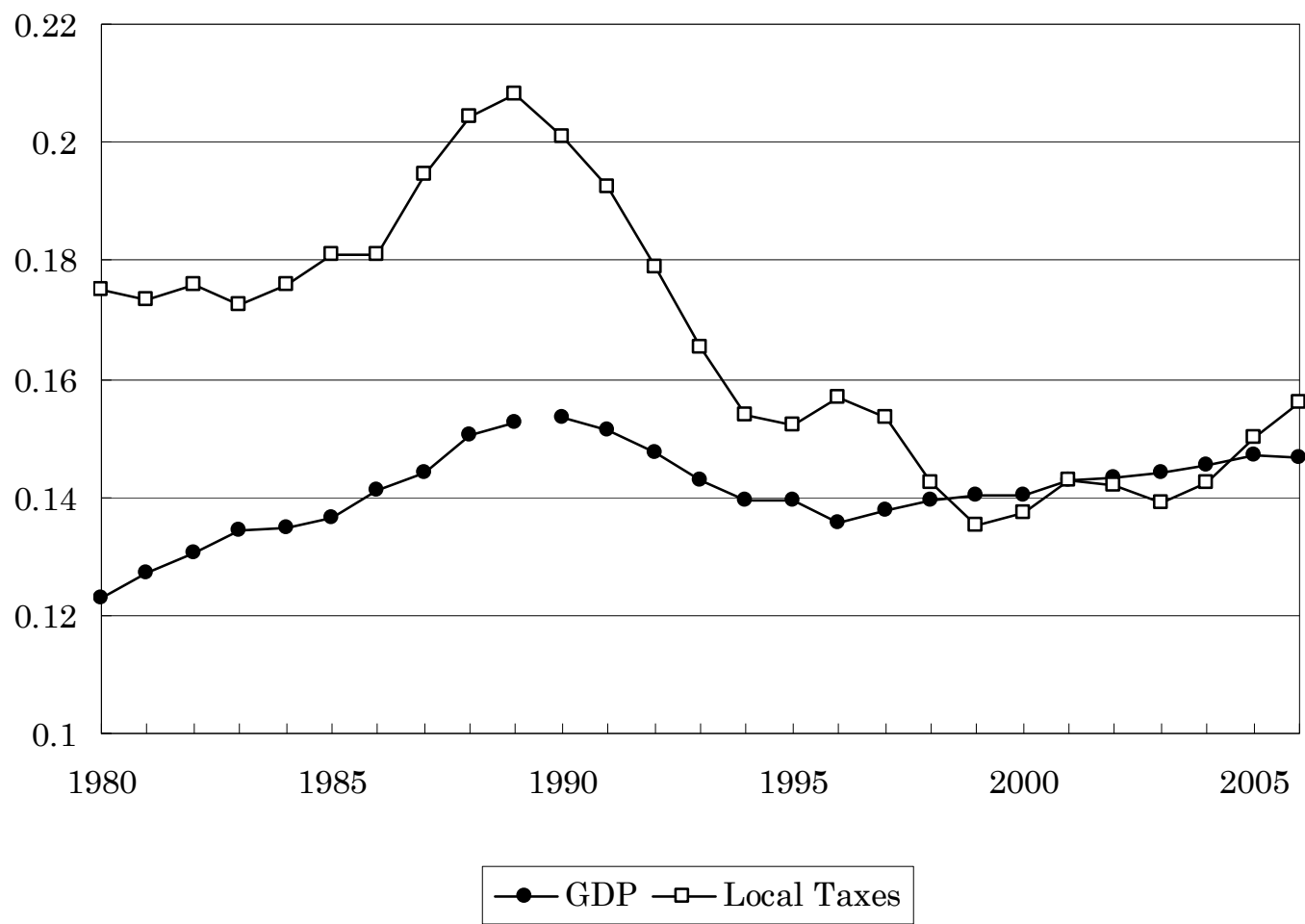

Note: From 1990, prefectural GDP is based on System of National Accounts 1993 (93SNA). From 1980 to 1989, it is taken from data based on the old standard of SNA (68SNA).

Source: Cabinet Office “Annual Report on Prefectural Accounts," Ministry of Internal Affairs and Communications "Annual Statistical Report on Local Government Finance," and "Basic Resident Registers." 
Figure 2

Micro-Allocation Rule of the LAT Grants

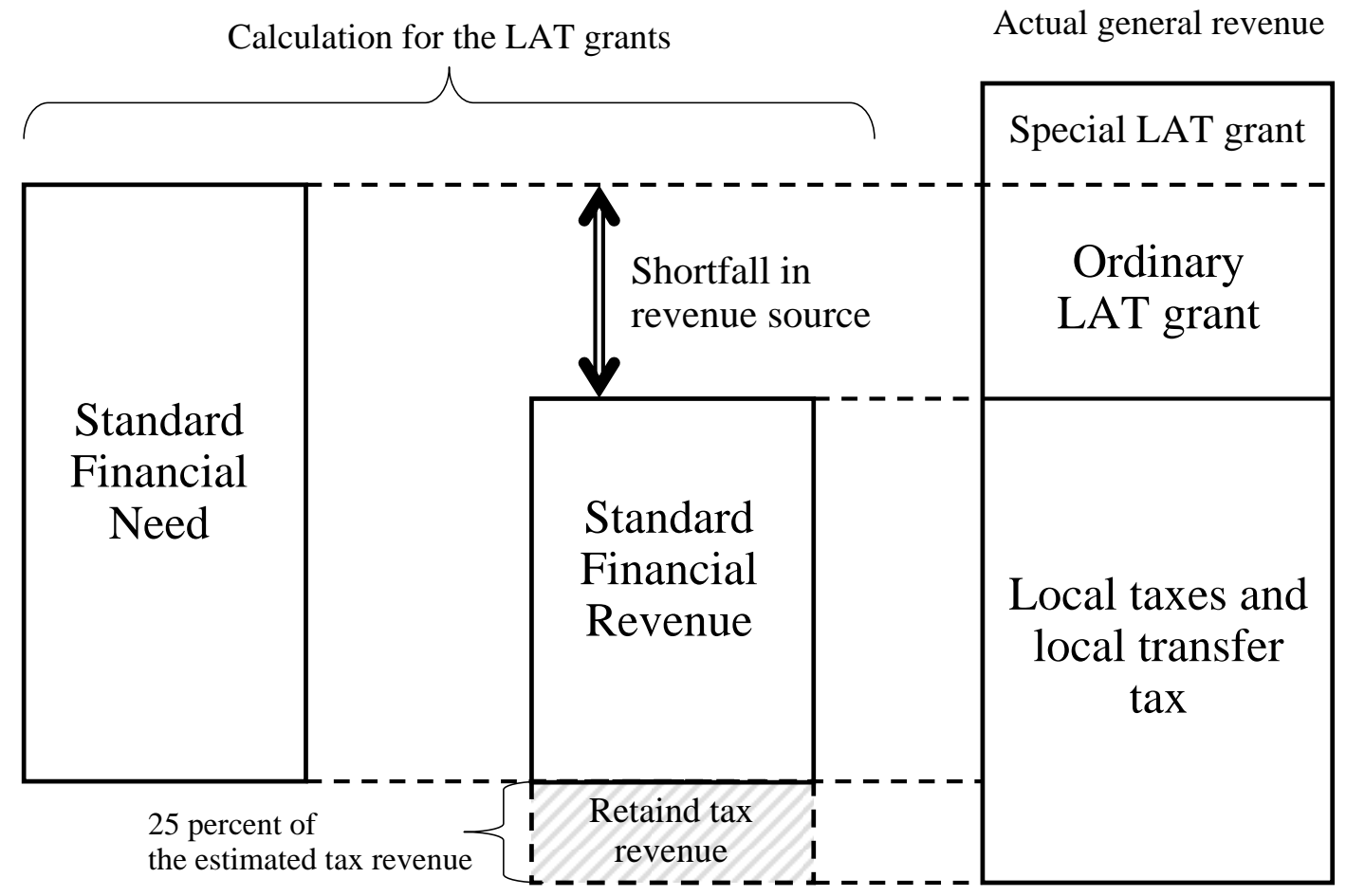

Source: Doi and Ihori (2009) 
Figure 3

Poverty Traps

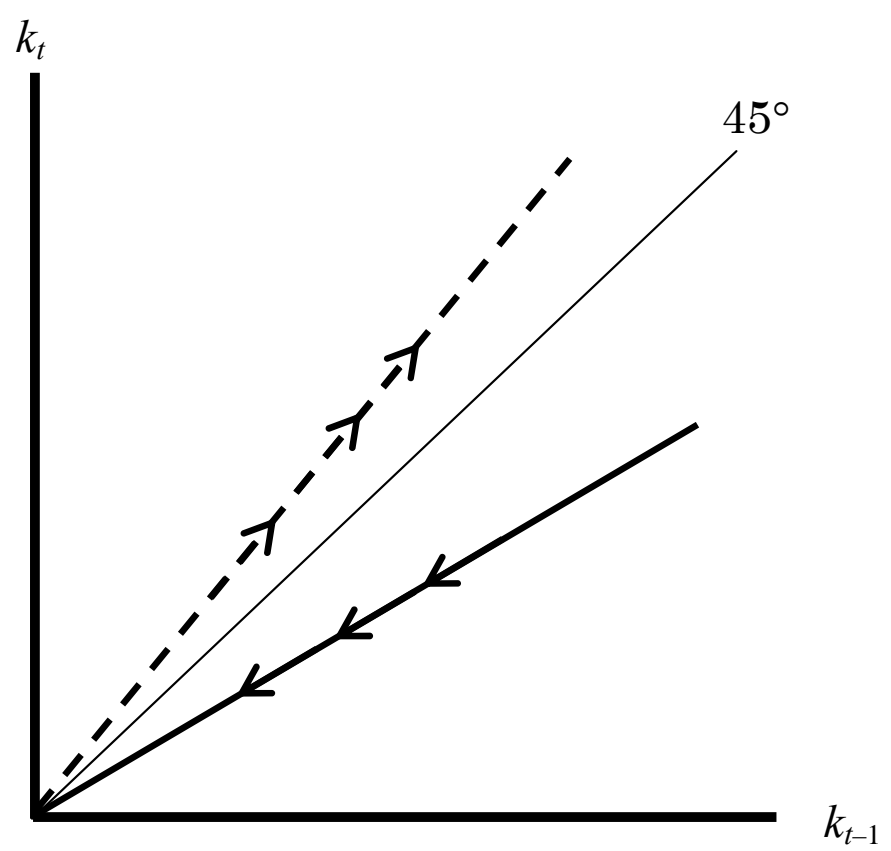


Figure 4

Accumulated Impulse Responses of GDP and LATGT to One Standard Deviation Shock of LATGT

Accumulated Impulse Response of LATGT

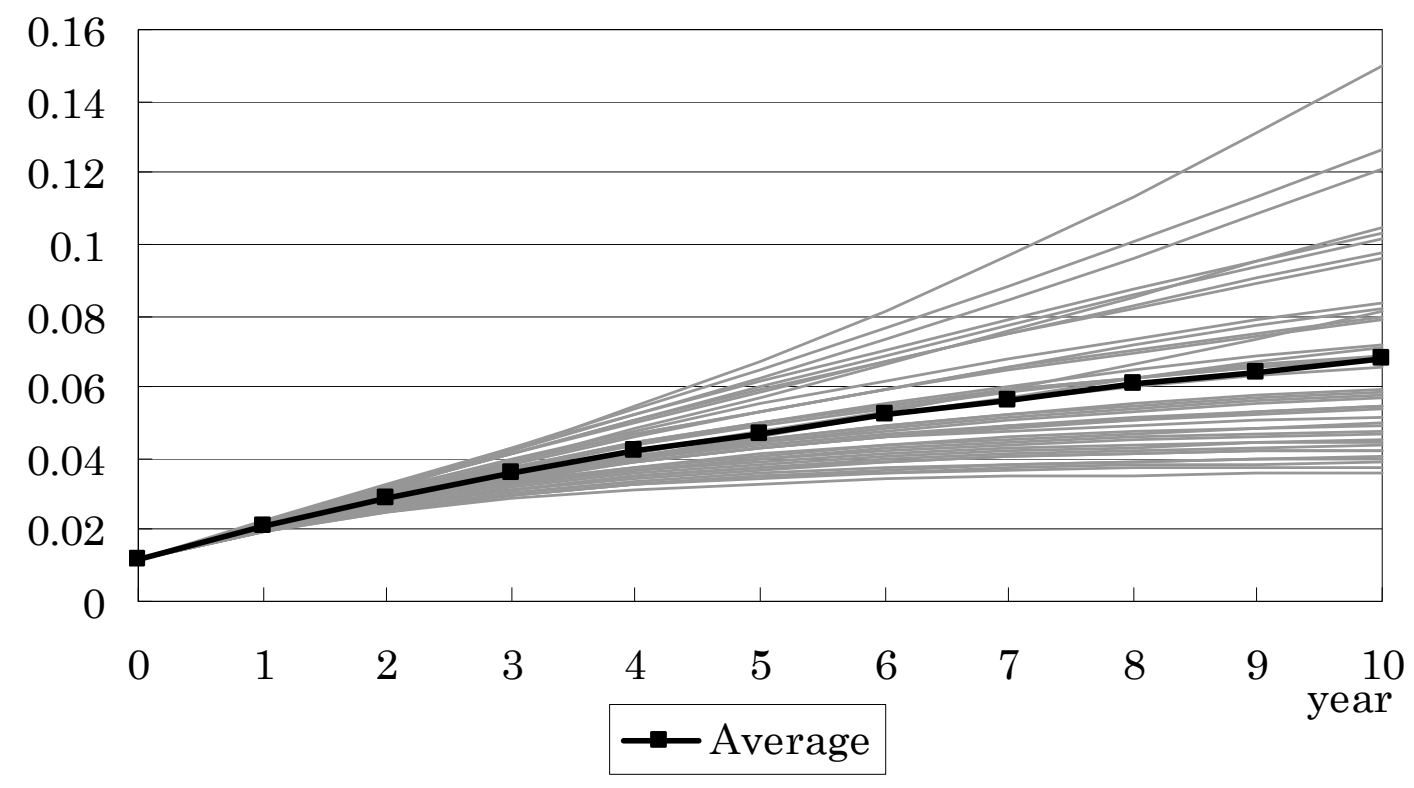

Accumulated Impulse Response of Prefectural GDP

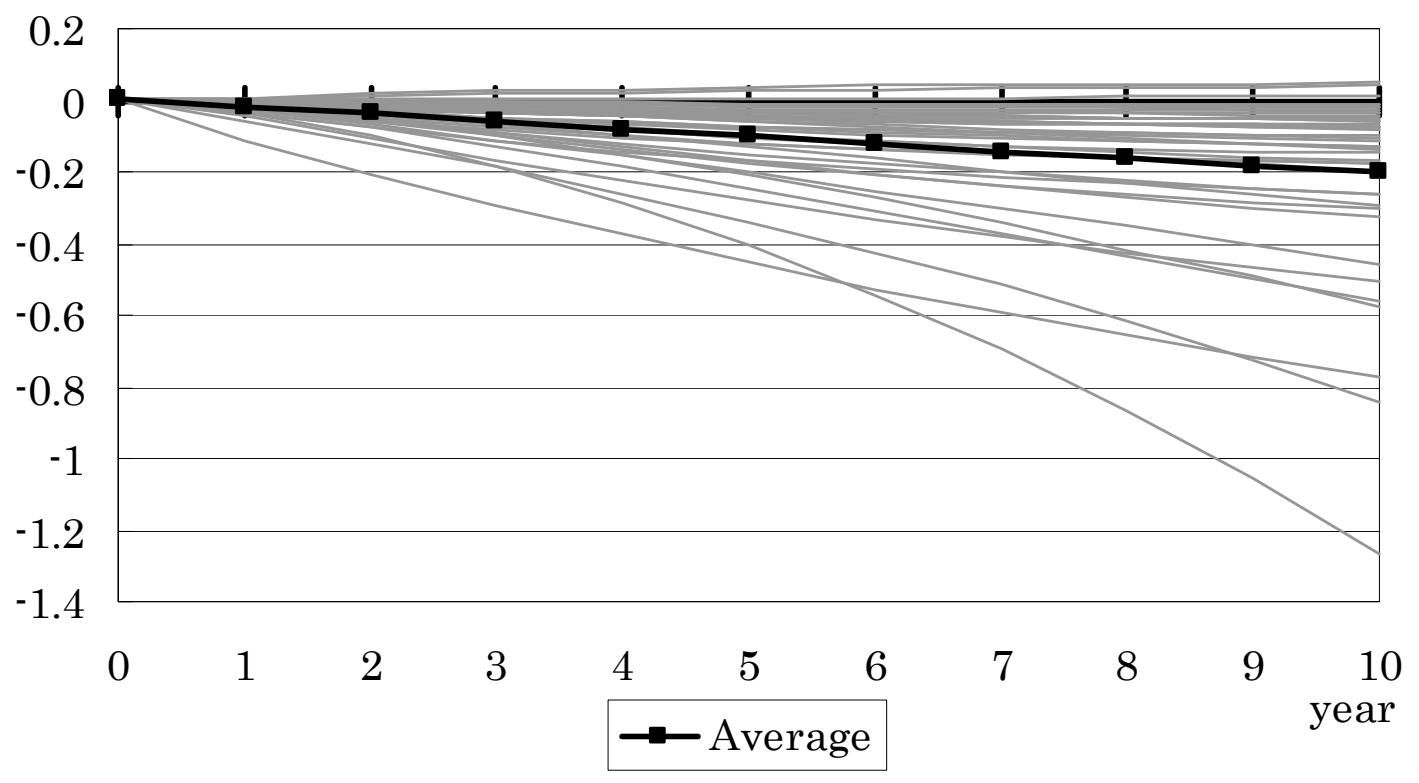


Table 1

Calculation of the Standard Financial Need (Outline)

Police expenses $=$

unit cost of police officer * number of police officers * adjustment coefficient

Education expenses $=$

unit cost of teacher * number of teachers * adjustment coefficient

Public works expenses $=\ldots$

Agriculture, forestry, and fishery expenses $=\ldots$

Commerce and industry expenses $=\ldots$

Debt-service expenses $=\ldots$

Sum of the above amount $=$ the Standard Financial Need of this local government

Note: * means 'multiplied by'.

Source: Doi and Ihori (2009) 
Table 2

Unit Root Tests

\begin{tabular}{|c|c|c|}
\hline & Statistic & P-value \\
\hline GDP & -3.852 & 0.000 \\
\hline LATGP & -4.048 & 0.000 \\
\hline LATGT & -3.076 & 0.001 \\
\hline
\end{tabular}


Table 3

Schwarz Information Criterion for Identification

\begin{tabular}{|c|c|c|}
\hline \multicolumn{3}{|c|}{ Lag order } \\
\hline J=1 & J=2 & J=3 \\
\hline Dependent var.: GDP, Independent var.: GDP LATGP \\
\hline-1.389 & -0.770 & -0.137 \\
\hline Dependent var.: LATGP, Independent var.: GDP LATGP \\
\hline-5.944 & -5.569 & -4.908 \\
\hline Dependent var.: GDP, Independent var.: & -0.796 & -0.137 \\
\hline-1.419 & GDP LATGT \\
\hline Dependent var.: LATGT, Independent var.: GDP LATGT \\
\hline-5.102 & -4.687 & -3.896 \\
\hline
\end{tabular}


Table 4

Granger Non-causality Tests

\begin{tabular}{|c|c|c|}
\hline & Statistic & P-value \\
\hline \multicolumn{3}{|c|}{ LATGP to GDP } \\
\hline$W_{N, T}^{H n c}$ & 4.403 & - \\
\hline$\tilde{Z}_{N, T}^{H n c}$ & 11.282 & 0.000 \\
\hline \multicolumn{3}{|c|}{ GDP to LATGP } \\
\hline$W_{N, T}^{H n c}$ & 4.488 & - \\
\hline$\tilde{Z}_{N, T}^{H n c}$ & 11.578 & 0.000 \\
\hline \multicolumn{3}{|c|}{ LATGT to GDP } \\
\hline$W_{N, T}^{H n c}$ & 5.332 & - \\
\hline$\tilde{Z}_{N, T}^{H n c}$ & 14.521 & 0.000 \\
\hline \multicolumn{3}{|c|}{ GDP to LATGT } \\
\hline$W_{N, T}^{H n c}$ & 1.795 & - \\
\hline$\tilde{Z}_{N, T}^{H n c}$ & 2.191 & 0.014 \\
\hline
\end{tabular}


Table 5-1

Estimation Results

Dependent var.: GDP, Independent var.: GDP LATGP

\begin{tabular}{|c|c|c|c|c|}
\hline Prefecture & & oefficient & t-Statistic & $\mathrm{P}$-value \\
\hline Hokkaido & $\alpha_{1}{ }^{1}$ & 0.0242 & 0.2456 & 0.8061 \\
\hline Aomori & $\alpha_{2}{ }^{1}$ & 0.4353 & 5.7745 & 0.0000 \\
\hline Iwate & $\alpha_{3}{ }^{1}$ & 0.5399 & 11.6317 & 0.0000 \\
\hline Miyagi & $\alpha_{4}{ }^{1}$ & 0.1480 & 2.9881 & 0.0029 \\
\hline Akita & $\alpha_{5}{ }^{1}$ & 0.4953 & 6.8520 & 0.0000 \\
\hline Yamagata & $\alpha_{6}{ }^{1}$ & 0.6386 & 5.9145 & 0.0000 \\
\hline Fukushima & $\alpha_{7}{ }^{1}$ & 0.6446 & 7.7492 & 0.0000 \\
\hline Ibaraki & $\alpha_{8}{ }^{1}$ & 0.2556 & 1.9931 & 0.0467 \\
\hline Tochigi & $\alpha_{9}{ }^{1}$ & 585 & 7.3510 & 0.0000 \\
\hline Gunma & $\alpha_{10}{ }^{1}$ & 47 & 032 & 0.0166 \\
\hline Saitama & $\alpha_{11}{ }^{1}$ & 289 & 3.2241 & 0013 \\
\hline Chiba & $\alpha_{12}{ }^{1}$ & & & \\
\hline Niigata & $\alpha_{15}{ }^{1}$ & 54 & 32 & 0.0000 \\
\hline Toyama & $\alpha_{16}{ }^{1}$ & 473 & 48 & 0.0000 \\
\hline Ishikawa & $\alpha_{17}{ }^{1}$ & 450 & 957 & 0.0000 \\
\hline Fukui & $\alpha_{18}{ }^{1}$ & 51 & 78 & 0000 \\
\hline Yamanas & $\alpha_{19}{ }^{1}$ & & 10. & \\
\hline Nagano & $\alpha_{20}{ }^{1}$ & & & 0000 \\
\hline Gifu & $\alpha_{21}{ }^{1}$ & 33 & 38 & 0.0001 \\
\hline Shizuoka & $\alpha_{22}{ }^{1}$ & 380 & 718 & 0006 \\
\hline Mie & $\alpha_{24}{ }^{1}$ & 97 & 19.5 & 0.0000 \\
\hline Shiga & $\alpha_{25}{ }^{1}$ & & & 0.0001 \\
\hline Kyoto & $\alpha_{26}{ }^{1}$ & & & 0.0174 \\
\hline Hyogo & $\alpha_{28}{ }^{1}$ & 980 & 414 & 0.0254 \\
\hline Nara & $\alpha_{29}{ }^{1}$ & 640 & 595 & 0.0044 \\
\hline Wakayama & $\alpha_{30}{ }^{1}$ & 349 & 2.9625 & 0.0032 \\
\hline Tottori & $\alpha_{31}{ }^{1}$ & 94 & 337 & 0004 \\
\hline Shimane & $\alpha_{32}{ }^{1}$ & 168 & 11.7 & 0.0000 \\
\hline Okayan & $\alpha_{33}{ }^{1}$ & & 572 & 0.0638 \\
\hline Hiroshima & $\alpha_{34}{ }^{1}$ & & 743 & 0.0946 \\
\hline Yamaguchi & $\alpha_{35}{ }^{1}$ & 0.4324 & 6.0527 & 0.0000 \\
\hline Tokushima & $\alpha_{36}{ }^{1}$ & 0.6483 & 14.9340 & 0.0000 \\
\hline Kagawa & $\alpha_{37}^{1}$ & 0.4520 & 6.5559 & 0.0000 \\
\hline Ehime & $\alpha_{38}{ }^{1}$ & 0.4866 & 555 & 0.0000 \\
\hline Kochi & $\alpha_{39}{ }^{1}$ & 0.3116 & 2.3763 & 0.0178 \\
\hline Fukuoka & $\alpha_{40}{ }^{1}$ & 0.3337 & 5.7401 & 0.0000 \\
\hline Saga & $\alpha_{41}^{1}$ & 0.5271 & 13.9542 & 0.0000 \\
\hline Nagasaki & $\alpha_{42}{ }^{1}$ & 0.2988 & 6.3770 & 0.0000 \\
\hline Kumamoto & $\alpha_{43}{ }^{1}$ & 0.2951 & 2.8491 & 0.0045 \\
\hline Oita & $\alpha_{44}{ }^{1}$ & 0.6598 & 10.7745 & 0.0000 \\
\hline Miyazaki & $\alpha_{45}{ }^{1}$ & 0.2601 & 3.3938 & 0.0007 \\
\hline Kagoshima & $\alpha_{46}{ }^{1}$ & 0.1751 & 1.0932 & 0.2747 \\
\hline Okinawa & $\alpha_{47}^{1}$ & 0.2265 & 3.0815 & 0.0022 \\
\hline
\end{tabular}

Adjusted R-squared $\quad 0.9767$ Standard error of regression $\quad 0.0741$

\begin{tabular}{|c|c|c|c|}
\hline & Coefficient & t-Statistic & $\mathrm{P}$-value \\
\hline$\beta_{1}{ }^{1}$ & \begin{tabular}{|l|}
-1.7196 \\
\end{tabular} & -1.1880 & 0.2353 \\
\hline$\beta_{2}{ }^{1}$ & -1.5271 & -1.5834 & 139 \\
\hline$\beta_{3}{ }^{1}$ & -2.2328 & -2.1288 & 0.0337 \\
\hline$\beta_{4}{ }^{1}$ & -1.5085 & -1.5849 & 0.1135 \\
\hline$\beta_{5}{ }^{1}$ & -1.5819 & -3.0924 & 0.0021 \\
\hline$\beta_{6}{ }^{1}$ & -1.0639 & -0.5998 & 0.5489 \\
\hline$\beta_{7}{ }^{1}$ & -1.2679 & -0.6344 & 0.5261 \\
\hline$\beta_{8}{ }^{1}$ & -1.8748 & -1.0241 & 3062 \\
\hline$\beta_{9}{ }^{1}$ & -0.9013 & -0.6018 & 475 \\
\hline$\beta_{10}{ }^{1}$ & -2.0215 & -1.2 & 052 \\
\hline$\beta_{11}{ }^{1}$ & -7.1 & -4.7876 & 0.0000 \\
\hline$\beta_{12}{ }^{1}$ & -12.9219 & -4.3602 & 0.0000 \\
\hline$\beta_{15}{ }^{1}$ & -1.1926 & -1.2687 & 0.2050 \\
\hline$\beta_{16}{ }^{1}$ & -1.1 & -0.9 & 565 \\
\hline$\beta_{17}{ }^{1}$ & -0.5 & -0. & $\overline{073}$ \\
\hline$\beta_{18}{ }^{1}$ & -0.1 & -0.2 & 402 \\
\hline$\beta_{19}{ }^{1}$ & -2.3301 & -1.5865 & 132 \\
\hline$\beta_{20}{ }^{1}$ & -2.4121 & -0.9083 & 0.3641 \\
\hline$\beta_{21}{ }^{1}$ & -1.6221 & -1.1450 & 527 \\
\hline$\beta_{22}{ }^{1}$ & 0.9 & 0.2 & 860 \\
\hline$\beta_{24}{ }^{1}$ & -3.8 & -1.2 & \\
\hline$\beta_{25}{ }^{1}$ & -3.4 & -1.5 & 154 \\
\hline$\beta_{26}{ }^{1}$ & -2.9183 & -2.0236 & 435 \\
\hline$\beta_{28}{ }^{1}$ & -6.7377 & -5.7448 & 0.0000 \\
\hline$\beta_{29}{ }^{1}$ & -2.1104 & -3.2823 & 011 \\
\hline$\beta_{30}{ }^{1}$ & -0.6 & -1.1 & 0.2640 \\
\hline$\beta_{31}{ }^{1}$ & -1.1 & -1.5 & 123 \\
\hline$\beta_{32}{ }^{1}$ & 0.7481 & 1.3254 & 856 \\
\hline$\beta_{33}{ }^{1}$ & -5.8094 & -4.5463 & 0.0000 \\
\hline$\beta_{34}{ }^{1}$ & -3.5505 & -2.1975 & 0.0284 \\
\hline$\beta_{35}{ }^{1}$ & -0.3 & -0.2583 & 0.7962 \\
\hline$\beta_{36}{ }^{1}$ & 0.6427 & 0.8777 & 3804 \\
\hline$\beta_{37}{ }^{1}$ & -0.4427 & -0.4970 & 3194 \\
\hline$\beta_{38}{ }^{1}$ & -1.4711 & -0.9065 & 0.3650 \\
\hline$\beta_{39}{ }^{1}$ & -0.0423 & -0.0354 & 0.9718 \\
\hline$\beta_{40}^{1}$ & -3.9411 & -2.6574 & 0.0081 \\
\hline$\beta_{41}{ }^{1}$ & -2.2678 & -3.6464 & 0.0003 \\
\hline$\beta_{42}{ }^{1}$ & -1.5640 & -3.1211 & 0.0019 \\
\hline$\beta_{43}{ }^{1}$ & 0.3343 & 0.2718 & 0.7859 \\
\hline$\beta_{44}{ }^{1}$ & 0.0889 & 0.0448 & 0.9643 \\
\hline$\beta_{45}{ }^{1}$ & -0.1410 & -0.1510 & 0.8800 \\
\hline$\beta_{46}{ }^{1}$ & 0.6953 & 0.3002 & 0.7641 \\
\hline$\beta_{47}{ }^{1}$ & -0.0758 & -0.1644 & 0.8695 \\
\hline
\end{tabular}

Log likelihood

936.1615

Schwarz criterion $\quad-1.3886$ 
Table 5-2

Estimation Results

Dependent var.: LATGP, Independent var.: GDP LATGP

\begin{tabular}{l|l|l|l}
\hline & Coefficient & t-Statistic & P-value \\
\hline$\gamma_{1}{ }^{1}$ & -0.0108 & -1.2414 & 0.2149 \\
\hline$\gamma_{2}{ }^{1}$ & -0.0116 & -1.0977 & 0.2728 \\
\hline$\gamma_{3}{ }^{1}$ & -0.0031 & -0.4474 & 0.6548 \\
\hline$\gamma_{4}{ }^{1}$ & -0.0048 & -1.1001 & 0.2717 \\
\hline$\gamma_{5}{ }^{1}$ & -0.0066 & -0.7382 & 0.4607 \\
\hline$\gamma_{6}{ }^{1}$ & -0.0024 & -0.4675 & 0.6403 \\
\hline$\gamma_{7}{ }^{1}$ & -0.0048 & -0.9793 & 0.3278 \\
\hline$\gamma_{8}{ }^{1}$ & -0.0324 & -3.1788 & 0.0016 \\
\hline$\gamma_{9}{ }^{1}$ & -0.0159 & -3.5183 & 0.0005 \\
\hline$\gamma_{10}{ }^{1}$ & -0.0086 & -1.1092 & 0.2678 \\
\hline$\gamma_{11}{ }^{1}$ & -0.0291 & -3.8095 & 0.0002 \\
\hline$\gamma_{12}{ }^{1}$ & -0.0170 & -1.0828 & 0.2794 \\
\hline$\gamma_{15}{ }^{1}$ & -0.0085 & -1.5789 & 0.1149 \\
\hline$\gamma_{16}{ }^{1}$ & -0.0203 & -3.2882 & 0.0011 \\
\hline$\gamma_{17}{ }^{1}$ & -0.0003 & -0.0472 & 0.9624 \\
\hline$\gamma_{18}{ }^{1}$ & -0.0107 & -1.4783 & 0.1399 \\
\hline$\gamma_{19}{ }^{1}$ & -0.0198 & -2.1934 & 0.0287 \\
\hline$\gamma_{20}{ }^{1}$ & -0.0007 & -0.1076 & 0.9143 \\
\hline$\gamma_{21}{ }^{1}$ & -0.0142 & -1.3903 & 0.1650 \\
\hline$\gamma_{22}{ }^{1}$ & -0.0119 & -2.6281 & 0.0088 \\
\hline$\gamma_{24}{ }^{1}$ & -0.0117 & -4.0176 & 0.0001 \\
\hline$\gamma_{25}{ }^{1}$ & -0.0224 & -2.6588 & 0.0081 \\
\hline$\gamma_{43}{ }^{1}$ & -0.0118 & -0.8107 & 0.4178 \\
\hline$\gamma_{45}{ }^{1}$ & -0.0096 & -2.1597 & 0.0312 \\
\hline$\gamma_{46}{ }^{1}$ & -0.0256 & -1.8422 & 0.0659 \\
\hline$\gamma_{28}{ }^{1}$ & -0.0131 & -1.3635 & 0.1732 \\
\hline$\gamma_{29}{ }^{1}$ & -0.0255 & -2.1314 & 0.0335 \\
\hline$\gamma_{30}{ }^{1}$ & -0.0262 & -3.2131 & 0.0014 \\
\hline$\gamma_{30}{ }^{1}$ & -0.0064 & -3.8154 & 0.0002 \\
\hline$\gamma_{36}{ }^{1}{ }^{1}$ & -0.0217 & -1.6954 & 0.0905 \\
\hline$\gamma_{32}{ }^{1}$ & -0.0021 & -0.2046 & 0.8380 \\
\hline$\gamma_{33}{ }^{1}$ & -0.0150 & -1.1322 & 0.2580 \\
\hline$\gamma_{34}{ }^{1}$ & -0.0241 & -1.8491 & 0.0649 \\
\hline$\gamma^{1}$ & -0.0228 & -4.2515 & 0.0000 \\
\hline${ }^{1}$ & -0.0091 & -2.1109 & 0.0352 \\
\hline
\end{tabular}

\begin{tabular}{l|r|r|l}
\hline & Coefficient & t-Statistic & P-value \\
\hline$\zeta_{1}{ }^{1}$ & 0.6629 & 5.5914 & 0.0000 \\
\hline$\zeta_{2}{ }^{1}$ & 0.6974 & 4.9947 & 0.0000 \\
\hline$\zeta_{3}{ }^{1}$ & 0.7288 & 6.2097 & 0.0000 \\
\hline$\zeta_{4}{ }^{1}$ & 0.6796 & 6.0846 & 0.0000 \\
\hline$\zeta_{5}{ }^{1}$ & 0.7780 & 6.7431 & 0.0000 \\
\hline$\zeta_{6}{ }^{1}$ & 0.7639 & 6.6438 & 0.0000 \\
\hline$\zeta_{7}{ }^{1}$ & 0.7747 & 6.3772 & 0.0000 \\
\hline$\zeta_{8}{ }^{1}$ & 0.8530 & 7.4145 & 0.0000 \\
\hline$\zeta_{9}{ }^{1}$ & 0.8922 & 11.1018 & 0.0000 \\
\hline$\zeta_{10}{ }^{1}$ & 0.7491 & 5.8438 & 0.0000 \\
\hline$\zeta_{11}{ }^{1}$ & 0.6810 & 6.3047 & 0.0000 \\
\hline$\zeta_{12}{ }^{1}$ & 0.4555 & 3.0319 & 0.0025 \\
\hline$\zeta_{15}{ }^{1}$ & 0.7891 & 7.6147 & 0.0000 \\
\hline$\zeta_{16}{ }^{1}$ & 0.8350 & 7.8779 & 0.0000 \\
\hline$\zeta_{17}{ }^{1}$ & 0.7571 & 6.2603 & 0.0000 \\
\hline$\zeta_{18}{ }^{1}$ & 0.8249 & 5.7209 & 0.0000 \\
\hline$\zeta_{19}{ }^{1}$ & 0.8861 & 6.0225 & 0.0000 \\
\hline$\zeta_{20}{ }^{1}$ & 0.7449 & 5.1125 & 0.0000 \\
\hline$\zeta_{21}{ }^{1}$ & 0.8294 & 6.4291 & 0.0000 \\
\hline$\zeta_{22}{ }^{1}$ & 0.8914 & 10.6931 & 0.0000 \\
\hline$\zeta_{24}{ }^{1}$ & 0.7438 & 6.4484 & 0.0000 \\
\hline$\zeta_{25}{ }^{1}$ & 0.7287 & 6.9106 & 0.0000 \\
\hline$\zeta_{26}{ }^{1}$ & 0.7504 & 9.1427 & 0.0000 \\
\hline$\zeta_{28}{ }^{1}$ & 0.6994 & 8.6214 & 0.0000 \\
\hline$\zeta_{29}{ }^{1}$ & 0.8329 & 8.2262 & 0.0000 \\
\hline$\zeta_{30}{ }^{1}$ & 0.8719 & 7.4471 & 0.0000 \\
\hline$\zeta_{31}{ }^{1}$ & 0.7511 & 4.0904 & 0.0000 \\
\hline$\zeta_{47}{ }^{1}$ & 0.8824 & 6.6202 & 0.0000 \\
\hline$\zeta_{32}{ }^{1}$ & 0.7672 & 4.3711 & 0.0000 \\
\hline$\zeta_{46}{ }^{1}$ & 0.6977 & 5.1146 & 0.0000 \\
\hline$\zeta_{33}{ }^{1}$ & 0.7234 & 5.7486 & 0.0000 \\
\hline$\zeta_{34}{ }^{1}$ & 0.7742 & 9.6688 & 0.0000 \\
\hline$\zeta_{35}{ }^{1}$ & 0.8788 & 8.1942 & 0.0000 \\
\hline$\zeta_{36}{ }^{1}$ & 0.7374 & 3.9215 & 0.0001 \\
\hline${ }^{1}{ }^{1}$ & 0.8296 & 4.7023 & 0.0000 \\
\hline${ }^{1}$ & 0.6830 & 4.0501 & 0.0001 \\
\hline$\zeta^{1}$ & 0.7908 & 4.8706 & 0.0000 \\
\hline
\end{tabular}

Adjusted R-squared $\quad 0.9817$ Standard error of regression $\quad 0.0076$

Log likelihood $\quad 2601.198$ Schwarz criterion $\quad-5.9441$ 
Table 5-3

Estimation Results

Dependent var.: GDP, Independent var.: GDP LATGT

\begin{tabular}{|c|c|c|c|}
\hline & Coefficient & $\mathrm{t}$-Statistic & $\mathrm{P}$-value \\
\hline$\alpha_{1}{ }^{1}$ & 0.0018 & \begin{tabular}{|l|}
0.0142 \\
\end{tabular} & 0.9887 \\
\hline$\alpha_{2}{ }^{1}$ & 0.4304 & 4.2938 & 0.0000 \\
\hline$\alpha_{3}{ }^{1}$ & 0.5275 & 9.2355 & 0.0000 \\
\hline$\alpha_{4}{ }^{1}$ & 0.1401 & 3.0311 & 0.0025 \\
\hline$\alpha_{5}{ }^{1}$ & 0.4901 & 6.3226 & 0.0000 \\
\hline$\alpha_{6}{ }^{1}$ & 0.6638 & 4.9862 & 0.0000 \\
\hline$\alpha_{7}{ }^{1}$ & 0.7073 & 8.0925 & 0.0000 \\
\hline$\alpha_{8}{ }^{1}$ & 0.2247 & 1.9922 & 0.0468 \\
\hline$\alpha_{9}{ }^{1}$ & 0.6588 & 8.4315 & 0.0000 \\
\hline$\alpha_{10}^{1}$ & 0.3999 & 2.9147 & 0.0037 \\
\hline$\alpha_{11}^{1}$ & 0.2760 & 2.3648 & 0.0184 \\
\hline$\alpha_{12}{ }^{1}$ & 0.1909 & 0.7145 & 0.4752 \\
\hline$\alpha_{15}{ }^{1}$ & 0.4146 & 6.8428 & 0.0000 \\
\hline$\alpha_{16}{ }^{1}$ & 0.3428 & 4.6749 & 0.0000 \\
\hline$\alpha_{17}{ }^{1}$ & 0.4859 & 3.6314 & 0.0003 \\
\hline$\alpha_{18}{ }^{1}$ & 0.5621 & 5.8513 & 0.0000 \\
\hline$\alpha_{19}{ }^{1}$ & 0.7887 & 10.0230 & 0.0000 \\
\hline$\alpha_{20}^{1}$ & 0.8013 & 4.9982 & 0.0000 \\
\hline$\alpha_{21}^{1}$ & 0.4813 & 4.4036 & 0.0000 \\
\hline$\alpha_{22}{ }^{1}$ & 0.6755 & 4.0242 & 0.0001 \\
\hline$\alpha_{24}{ }^{1}$ & 0.9861 & 20.1826 & 0.0000 \\
\hline$\alpha_{25}{ }^{1}$ & 0.6168 & \begin{tabular}{|l|}
4.3089 \\
\end{tabular} & 0.0000 \\
\hline$\alpha_{26}^{1}$ & 0.4359 & 2.5492 & 0.0110 \\
\hline$\alpha_{28}^{1}$ & 0.4255 & 2.4903 & 0.0130 \\
\hline$\alpha_{29}^{1}$ & 0.2424 & 2.5679 & 0.0105 \\
\hline$\alpha_{30}^{1}$ & 0.2039 & 2.7269 & 0.0066 \\
\hline$\alpha_{31}^{1}$ & 0.4292 & 3.3634 & 0.0008 \\
\hline$\alpha_{32}^{1}$ & 0.4919 & 8.4621 & 0.0000 \\
\hline$\alpha_{33}{ }^{1}$ & 0.2383 & 2.1769 & 0.0299 \\
\hline$\alpha_{34}{ }^{1}$ & 0.4075 & 1.9141 & 0.0561 \\
\hline$\alpha_{35}{ }^{1}$ & 0.4433 & 5.7558 & 0.0000 \\
\hline$\alpha_{36}{ }^{1}$ & 0.6312 & 14.3197 & 0.0000 \\
\hline$\alpha_{37}^{1}$ & 0.4345 & 6.0890 & 0.0000 \\
\hline$\alpha_{38}^{1}$ & 0.4433 & 5.5946 & 0.0000 \\
\hline$\alpha_{39}^{1}$ & 0.3094 & 1.7595 & 0.0790 \\
\hline$\alpha_{40}{ }^{1}$ & 0.2829 & 5.5520 & 0.0000 \\
\hline$\alpha_{41}{ }^{1}$ & 0.5322 & 14.2703 & 0.0000 \\
\hline$\alpha_{42}{ }^{1}$ & 0.2901 & 6.5524 & 0.0000 \\
\hline$\alpha_{43}{ }^{1}$ & 0.3037 & 3.4695 & 0.0006 \\
\hline$\alpha_{44}{ }^{1}$ & 0.6496 & 9.3584 & 0.0000 \\
\hline$\alpha_{45}{ }^{1}$ & 0.2332 & 3.2651 & 0.0012 \\
\hline$\alpha_{46}{ }^{1}$ & 0.2309 & 1.5165 & 0.1299 \\
\hline$\alpha_{47}^{1}$ & 0.1797 & 2.5845 & 0.0100 \\
\hline
\end{tabular}

Adjusted R-squared $\quad 0.9774$ Standard error of regression $\quad 0.0730$ 
Table 5-4

Estimation Results

Dependent var.: LATGT, Independent var.: GDP LATGT

\begin{tabular}{|c|c|c|c|}
\hline & Coefficient & t-Statistic & $\mathrm{P}$-value \\
\hline$\gamma_{1}{ }^{1}$ & 0.0074 & 0.5424 & 0.5878 \\
\hline$\gamma_{2}^{1}$ & -0.0026 & -0.2006 & 0.8411 \\
\hline$\gamma_{3}{ }^{1}$ & 0.0065 & 0.6637 & 0.5071 \\
\hline$\gamma_{4}{ }^{1}$ & 0.0044 & 0.6821 & 0.4954 \\
\hline$\gamma_{5}{ }^{1}$ & 0.0114 & 0.8562 & 0.3922 \\
\hline$\gamma_{6}{ }^{1}$ & 0.0073 & 0.7733 & 0.4396 \\
\hline$\gamma_{7}{ }^{1}$ & 0.0009 & 0.1240 & 0.9013 \\
\hline$\gamma_{8}{ }^{1}$ & -0.0332 & -2.0377 & 0.0420 \\
\hline$\gamma_{9}^{1}$ & -0.0150 & -2.6426 & 0.0084 \\
\hline$\gamma_{10}^{1}$ & -0.0054 & -0.4669 & 0.6407 \\
\hline$\gamma_{11}^{1}$ & -0.0428 & -3.1485 & 0.0017 \\
\hline${\underline{\gamma_{12}}}^{1}$ & -0.0207 & -0.9473 & 0.3439 \\
\hline$\gamma_{15}{ }^{1}$ & -0.0013 & -0.1327 & 0.8945 \\
\hline$\gamma_{16}{ }^{1}$ & -0.0179 & -1.6179 & 0.1062 \\
\hline$\gamma_{17}^{1}$ & 0.0116 & 0.8655 & 0.3871 \\
\hline$\gamma_{18}^{1}$ & -0.0097 & -0.8709 & 0.3841 \\
\hline$\gamma_{19}^{1}$ & -0.0205 & -1.6191 & 0.1059 \\
\hline$\gamma_{20}^{1}$ & 0.0043 & 0.2909 & 0.7713 \\
\hline$\gamma_{21}^{1}$ & -0.0141 & -0.8762 & 0.3813 \\
\hline$\gamma_{22}{ }^{1}$ & -0.0131 & -1.9886 & 0.0472 \\
\hline$\gamma_{24}{ }^{1}$ & -0.0109 & -2.2125 & 0.0273 \\
\hline$\gamma_{25}{ }^{1}$ & -0.0268 & -1.9524 & 0.0513 \\
\hline$\gamma_{26}^{1}$ & -0.0115 & -0.5054 & 0.6134 \\
\hline$\gamma_{28}^{1}$ & -0.0123 & -0.6545 & 0.5131 \\
\hline$\gamma_{29}^{1}$ & -0.0163 & -0.7475 & 0.4551 \\
\hline$\gamma_{30}^{1}$ & -0.0219 & -1.6751 & 0.0944 \\
\hline$\gamma_{31}^{1}$ & -0.0078 & -0.2794 & 0.7800 \\
\hline$\gamma_{32}^{1}$ & 0.0258 & 1.0251 & 0.3057 \\
\hline$\gamma_{33}{ }^{1}$ & -0.0124 & -0.6840 & 0.4942 \\
\hline$\gamma_{34}{ }^{1}$ & -0.0343 & -1.8462 & 0.0654 \\
\hline$\gamma_{35}{ }^{1}$ & -0.0242 & -2.5255 & 0.0118 \\
\hline$\gamma_{36}{ }^{1}$ & -0.0056 & -0.8345 & 0.4043 \\
\hline$\gamma_{37}^{1}$ & -0.0056 & -0.3770 & 0.7063 \\
\hline$\gamma_{38}^{1}$ & 0.0059 & 0.4267 & 0.6698 \\
\hline$\gamma_{39}{ }^{1}$ & 0.0062 & 0.2796 & 0.7799 \\
\hline$\gamma_{40}^{1}$ & -0.0071 & -0.6842 & 0.4941 \\
\hline$\gamma_{41}^{1}$ & 0.0005 & 0.0774 & 0.9383 \\
\hline$\gamma_{42}^{1}$ & 0.0033 & 0.4039 & 0.6864 \\
\hline$\gamma_{43}{ }^{1}$ & -0.0258 & -2.1739 & 0.0301 \\
\hline$\underline{\gamma}_{44}^{1}$ & -0.0058 & -0.6806 & 0.4964 \\
\hline$\gamma_{45}^{1}$ & -0.0244 & -1.3361 & 0.1820 \\
\hline$\gamma_{46}{ }^{1}$ & -0.0249 & -1.7787 & 0.0758 \\
\hline$\gamma_{47}^{1}$ & -0.0387 & -2.2055 & 0.0278 \\
\hline
\end{tabular}

Adjusted R-squared Standard error of regression
0.9844 0.0116

\begin{tabular}{|c|c|c|c|}
\hline & Coefficient & t-Statistic & $\mathrm{P}$-value \\
\hline$\zeta_{1}^{1}$ & 0.7115 & 5.3886 & 0.0000 \\
\hline$\zeta_{2}^{1}$ & 0.7171 & 5.2358 & 0.0000 \\
\hline$\zeta_{3}{ }^{1}$ & 0.7146 & 5.8037 & 0.0000 \\
\hline$\zeta_{4}{ }^{1}$ & 0.7506 & 6.3978 & 0.0000 \\
\hline$\zeta_{5}{ }^{1}$ & 0.7534 & 6.1770 & 0.0000 \\
\hline$\zeta_{6}{ }^{1}$ & 0.7733 & 6.0383 & 0.0000 \\
\hline$\zeta_{7}^{1}$ & 0.7759 & 6.0933 & 0.0000 \\
\hline$\zeta_{8}^{1}$ & 0.8962 & 8.4649 & 0.0000 \\
\hline$\zeta_{9}^{1}$ & 0.9106 & 9.3126 & 0.0000 \\
\hline$\zeta_{10}{ }^{1}$ & 0.8165 & 6.5559 & 0.0000 \\
\hline$\zeta_{11}{ }^{1}$ & 0.8219 & 8.3503 & 0.0000 \\
\hline$\zeta_{12}{ }^{1}$ & 0.6703 & 4.7520 & 0.0000 \\
\hline$\zeta_{15}{ }^{1}$ & 0.8247 & 7.4166 & 0.0000 \\
\hline$\zeta_{16}{ }^{1}$ & 0.8956 & 9.7129 & 0.0000 \\
\hline$\zeta_{17}{ }^{1}$ & 0.7657 & 5.8215 & 0.0000 \\
\hline$\zeta_{18}{ }^{1}$ & 0.8604 & 5.5828 & 0.0000 \\
\hline$\zeta_{19}{ }^{1}$ & 0.9173 & 6.5022 & 0.0000 \\
\hline$\zeta_{20}{ }^{1}$ & 0.8127 & 4.5485 & 0.0000 \\
\hline$\zeta_{21}{ }^{1}$ & 0.8747 & 6.1912 & 0.0000 \\
\hline$\zeta_{22}{ }^{1}$ & 0.9424 & 11.7514 & 0.0000 \\
\hline$\zeta_{24}{ }^{1}$ & 0.7898 & 7.1714 & 0.0000 \\
\hline$\zeta_{25}{ }^{1}$ & 0.8423 & 7.9764 & 0.0000 \\
\hline$\zeta_{26}{ }^{1}$ & 0.8414 & 9.4169 & 0.0000 \\
\hline$\zeta_{28}{ }^{1}$ & 0.8418 & 11.4081 & 0.0000 \\
\hline$\zeta_{29}{ }^{1}$ & 0.8736 & 8.1420 & 0.0000 \\
\hline$\zeta_{30}{ }^{1}$ & 0.8816 & 7.2079 & 0.0000 \\
\hline$\zeta_{31}{ }^{1}$ & 0.7971 & 4.2751 & 0.0000 \\
\hline$\zeta_{32}{ }^{1}$ & 0.6914 & 3.2807 & 0.0011 \\
\hline$\zeta_{33}{ }^{1}$ & 0.8110 & 9.4376 & 0.0000 \\
\hline$\zeta_{34}{ }^{1}$ & 0.8922 & 11.1276 & 0.0000 \\
\hline$\zeta_{35}{ }^{1}$ & 0.9175 & 7.7239 & 0.0000 \\
\hline$\zeta_{36}{ }^{1}$ & 0.7407 & 3.6183 & 0.0003 \\
\hline$\zeta_{37}{ }^{1}$ & 0.8058 & 4.8053 & 0.0000 \\
\hline$\zeta_{38}{ }^{1}$ & 0.6868 & 3.7887 & 0.0002 \\
\hline$\zeta_{39}{ }^{1}$ & 0.7843 & 4.7679 & 0.0000 \\
\hline$\zeta_{40}{ }^{1}$ & 0.7830 & 5.1509 & 0.0000 \\
\hline$\zeta_{41}{ }^{1}$ & 0.7545 & 5.6022 & 0.0000 \\
\hline$\zeta_{42}{ }^{1}$ & 0.7852 & 6.6077 & 0.0000 \\
\hline$\zeta_{43}{ }^{1}$ & 0.8394 & 6.9166 & 0.0000 \\
\hline$\zeta_{44}{ }^{1}$ & 0.8646 & 5.9651 & 0.0000 \\
\hline$\zeta_{45}{ }^{1}$ & 0.8119 & 6.4634 & 0.0000 \\
\hline$\zeta_{46}{ }^{1}$ & 0.8719 & 7.0104 & 0.0000 \\
\hline$\zeta_{47}^{1}$ & 0.8113 & 7.5950 & 0.0000 \\
\hline
\end{tabular}

Log likelihood $\quad 2293.596$ Schwarz criterion $\quad-5.1025$ 
Table 5-5

Estimation Results

Dependent var.: GDP, Independent var.: GDP LATGT

\begin{tabular}{|c|c|c|c|c|}
\hline Prefecture & & oefficient & t-Statistic & $\mathrm{P}$-value \\
\hline Hokkaido & $\alpha_{1}{ }^{1}$ & 0.0369 & 0.3127 & 0.7546 \\
\hline Aomori & $\alpha_{2}{ }^{1}$ & 0.4583 & 4.5717 & 0.0000 \\
\hline Iwate & $\alpha_{3}{ }^{1}$ & 0.5472 & 9.6821 & 0.0000 \\
\hline Miyagi & $\alpha_{4}{ }^{1}$ & 0.1651 & 3.5204 & 0.0005 \\
\hline Akita & $\alpha_{5}{ }^{1}$ & 0.5144 & 6.5270 & 0.0000 \\
\hline Yamagata & $\alpha_{6}{ }^{1}$ & 0.6814 & 5.0726 & 0.0000 \\
\hline Fukushima & $\alpha_{7}{ }^{1}$ & 0.7234 & 8.2058 & 0.0000 \\
\hline Ibaraki & $\alpha_{8}{ }^{1}$ & 0.2618 & 2.3018 & 0.0217 \\
\hline Tochigi & $\alpha_{9}{ }^{1}$ & 0.6766 & 8.6309 & 0.0000 \\
\hline Gunma & $\alpha_{10}{ }^{1}$ & 0.4272 & 3.0564 & 0.0023 \\
\hline Saitama & $\alpha_{11}{ }^{1}$ & 0.3124 & 2.6914 & 0.0073 \\
\hline Chiba & $\alpha_{12}{ }^{1}$ & 0.2091 & 0.8016 & 0.4231 \\
\hline Tokyo & $\alpha_{13}{ }^{1}$ & 0.6399 & 9.2714 & 0.0000 \\
\hline Kanagawa & $\alpha_{14}{ }^{1}$ & -0.2394 & -1.5334 & 0.1257 \\
\hline Niigata & $\alpha_{15}{ }^{1}$ & 0.4339 & 7.2739 & 0.0000 \\
\hline Toyama & $\alpha_{16}{ }^{1}$ & 0.3574 & 4.6868 & 0.0000 \\
\hline Ishikawa & $\alpha_{17}{ }^{1}$ & 24 & 3.6877 & 0.0002 \\
\hline Fukui & $\alpha_{18}{ }^{1}$ & 0.5781 & 5.9539 & 0.0000 \\
\hline Yamanashi & $\alpha_{19}{ }^{1}$ & 0.8080 & 10.2942 & 0.0000 \\
\hline Nagano & $\alpha_{20}{ }^{1}$ & 0.8150 & 5.0533 & 0.0000 \\
\hline Gifu & $\alpha_{21}{ }^{1}$ & 0.5103 & 4.6354 & 0.0000 \\
\hline Shizuoka & $\alpha_{22}{ }^{1}$ & 0.6900 & 4.1073 & 0.0000 \\
\hline Aichi & $\alpha_{23}{ }^{1}$ & 0.7702 & 8.1217 & 0.0000 \\
\hline Mie & $\alpha_{24}{ }^{1}$ & 0.9989 & 20.5617 & 0.0000 \\
\hline Shiga & $\alpha_{25}{ }^{1}$ & 0.6285 & 4.3655 & 0.0000 \\
\hline Kyoto & $\alpha_{26}{ }^{1}$ & 0.4469 & 2.5773 & 0.0102 \\
\hline Osaka & $\alpha_{27}{ }^{1}$ & 0.0537 & 1.3000 & 0.1941 \\
\hline Hyogo & $\alpha_{28}{ }^{1}$ & 0.4298 & 2.5533 & 0.0109 \\
\hline Nara & $\alpha_{29}{ }^{1}$ & 0.2749 & 2.9929 & 0.0029 \\
\hline Wakayama & $\alpha_{30}{ }^{1}$ & 0.2319 & 2.9821 & 0.0030 \\
\hline Tottori & $\alpha_{31}{ }^{1}$ & 0.4580 & 3.5772 & 0.0004 \\
\hline Shimane & $\alpha_{32}{ }^{1}$ & 0.5152 & 8.8422 & 0.0000 \\
\hline Okayama & $\alpha_{33}{ }^{1}$ & 0.2494 & 2.2047 & 0.0278 \\
\hline Hiroshima & $\alpha_{34}{ }^{1}$ & 0.4264 & 1.9833 & 0.0477 \\
\hline Yamaguchi & $\alpha_{35}{ }^{1}$ & 0.4620 & 5.9630 & 0.0000 \\
\hline Tokushima & $\alpha_{36}{ }^{1}$ & 0.6474 & 14.8594 & 0.0000 \\
\hline Kagawa & $\alpha_{37}{ }^{1}$ & 0.4552 & 6.5152 & 0.0000 \\
\hline Ehime & $\alpha_{38}{ }^{1}$ & 0.4641 & 5.8687 & 0.0000 \\
\hline Kochi & $\alpha_{39}{ }^{1}$ & 0.3349 & 1.9595 & 0.0505 \\
\hline Fukuoka & $\alpha_{40}{ }^{1}$ & 0.3145 & 6.3873 & 0.0000 \\
\hline Saga & $\alpha_{41}{ }^{1}$ & 0.5535 & 15.2296 & 0.0000 \\
\hline Nagasaki & $\alpha_{42}{ }^{1}$ & 0.3087 & 6.8681 & 0.0000 \\
\hline Kumamoto & $\alpha_{43}{ }^{1}$ & 0.3356 & 3.8072 & 0.0002 \\
\hline Oita & $\alpha_{44}{ }^{1}$ & 0.6662 & 9.5517 & 0.0000 \\
\hline Miyazaki & $\alpha_{45}{ }^{1}$ & 0.2712 & 3.8662 & 0.0001 \\
\hline Kagoshima & $\alpha_{46}{ }^{1}$ & 0.2524 & 1.6447 & 0.1005 \\
\hline Okinawa & $\alpha_{47}^{1}$ & 0.2232 & 3.2949 & 0.0010 \\
\hline
\end{tabular}

\begin{tabular}{|c|c|c|c|}
\hline & Coefficient & t-Statistic & $\mathrm{P}$-value \\
\hline$\beta_{1}{ }^{1}$ & -0.2438 & -0.2896 & 0.7722 \\
\hline$\beta_{2}{ }^{1}$ & -0.7144 & -0.8534 & .3938 \\
\hline$\beta_{3}{ }^{1}$ & -1.2080 & -1.3590 & .1746 \\
\hline$\beta_{4}{ }^{1}$ & -0.9722 & -1.5358 & .1251 \\
\hline$\beta_{5}{ }^{1}$ & -0.8561 & -2.5355 & 0115 \\
\hline$\beta_{6}{ }^{1}$ & -1.0101 & -0.7 & 250 \\
\hline$\beta_{7}{ }^{1}$ & -2.0481 & 158 & 867 \\
\hline$\beta_{8}{ }^{1}$ & -1.5 & -1. & 084 \\
\hline$\beta_{9}{ }^{1}$ & -1.2 & 315 & 005 \\
\hline$\beta_{10}{ }^{1}$ & -1.8 & 822 & 228 \\
\hline$\beta_{11}{ }^{1}$ & -4.6 & -4. & 000 \\
\hline$\beta_{12}{ }^{1}$ & -9.1 & -4 . & 000 \\
\hline$\beta_{13}{ }^{1}$ & -6.4 & -0. & 616 \\
\hline$\beta_{14}{ }^{1}$ & -7. & -4 . & 000 \\
\hline$\beta_{15}{ }^{1}$ & -1. & -1. & 527 \\
\hline$\beta_{16}{ }^{1}$ & -0. & -0. & 892 \\
\hline$\beta_{17}{ }^{1}$ & 0. & 93 & 971 \\
\hline$\beta_{18}{ }^{1}$ & -0. & -0. & 649 \\
\hline$\beta_{19}{ }^{1}$ & -1.6 & -1. & 037 \\
\hline$\beta_{20}{ }^{1}$ & -1. & -0 & 268 \\
\hline$\beta_{21}{ }^{1}$ & -1.2 & -1. & 969 \\
\hline$\beta_{22}{ }^{1}$ & -0. & -0 . & 533 \\
\hline$\beta_{23}{ }^{1}$ & -3. & -2. & 937 \\
\hline$\beta_{24}{ }^{1}$ & -2. & -1. & 978 \\
\hline$\beta_{25}{ }^{1}$ & -2. & -1 . & 506 \\
\hline$\beta_{26}{ }^{1}$ & -2. & -2. & 146 \\
\hline$\beta_{27}{ }^{1}$ & -2. & -4 . & 00 \\
\hline$\beta_{28}{ }^{1}$ & -3. & -5. & 000 \\
\hline$\beta_{29}{ }^{1}$ & -1. & -3 & 012 \\
\hline & -0. & -1. & 150 \\
\hline$\beta_{31}{ }^{1}$ & -0. & -1. & 365 \\
\hline$\beta_{32}{ }^{1}$ & & 50 & 635 \\
\hline$\beta_{33}{ }^{1}$ & -3. & -4. & 00 \\
\hline$\beta_{34}{ }^{1}$ & 52 & -2 . & 73 \\
\hline$\beta_{35}{ }^{1}$ & -0. & -0. & 270 \\
\hline$\beta_{36}{ }^{1}$ & & $\mathrm{O} 4$ & 372 \\
\hline$\beta_{37}{ }^{1}$ & -0. & -0. & 589 \\
\hline$\beta_{38}{ }^{1}$ & -0.4 & -0. & 0.6851 \\
\hline$\beta_{39}{ }^{1}$ & -0.2 & -0.2 & 0.8047 \\
\hline$\beta_{40}{ }^{1}$ & -2.31 & -3. & 0.0016 \\
\hline$\beta_{41}{ }^{1}$ & -1.57 & 816 & 0.0004 \\
\hline$\beta_{42}{ }^{1}$ & -0.9147 & -2.8658 & 0.0043 \\
\hline$\beta_{43}{ }^{1}$ & -0.7528 & -1.1430 & 0.2535 \\
\hline$\beta_{44}{ }^{1}$ & -0.1050 & -0.0758 & 0.9396 \\
\hline$\beta_{45}{ }^{1}$ & -0.2738 & -0.5292 & 0.5969 \\
\hline$\beta_{46}{ }^{1}$ & -0.5178 & -0.4594 & 0.6461 \\
\hline$\beta_{47}{ }^{1}$ & -0.1472 & -0.6350 & 0.5257 \\
\hline
\end{tabular}

Adjusted R-squared

0.9907 Standard error of regression

0.0755

Log likelihood $\quad 1008.395$ Schwarz criterion $\quad-1.3364$ 


\section{Table 5-6 \\ Estimation Results}

Dependent var.: LATGT, Independent var.: GDP LATGT

\begin{tabular}{|c|c|c|c|}
\hline & Coefficient & $\mathrm{t}-$ Statistic & P-value \\
\hline$\gamma_{1}{ }^{1}$ & $\begin{array}{ll}0.0068 \\
\end{array}$ & \begin{tabular}{|l|}
0.5033 \\
\end{tabular} & 0.6149 \\
\hline$\gamma_{2}^{1}$ & -0.0031 & -0.2366 & 0.8130 \\
\hline$\gamma_{3}{ }^{1}$ & 0.0062 & 0.6386 & 0.5233 \\
\hline$\gamma_{4}{ }^{1}$ & 0.0041 & 0.6320 & 0.5276 \\
\hline$\gamma_{5}{ }^{1}$ & 0.0110 & 0.8320 & 0.4057 \\
\hline$\gamma_{6}{ }^{1}$ & 0.0070 & 0.7483 & 0.4545 \\
\hline$\gamma_{7}{ }^{1}$ & 0.0007 & 0.0912 & 0.9274 \\
\hline$\gamma_{8}{ }^{1}$ & -0.0338 & -2.1000 & 0.0361 \\
\hline$\gamma_{9}{ }^{1}$ & -0.0153 & -2.7420 & 0.0063 \\
\hline$\gamma_{10}^{1}$ & -0.0059 & -0.5074 & 0.6121 \\
\hline$\gamma_{11}^{1}$ & -0.0434 & -3.2521 & 0.0012 \\
\hline$\gamma_{12}{ }^{1}$ & -0.0210 & -0.9613 & 0.3368 \\
\hline$\gamma_{13}^{1}$ & -0.0058 & -2.3765 & 0.0178 \\
\hline$\gamma_{14}{ }^{1}$ & -0.0063 & -0.6898 & 0.4905 \\
\hline$\gamma_{15}^{1}$ & -0.0016 & -0.1654 & 0.8687 \\
\hline$\gamma_{16}{ }^{1}$ & -0.0181 & -1.6375 & 0.1020 \\
\hline$\gamma_{17}^{1}$ & 0.0114 & 0.8486 & 0.3964 \\
\hline$\gamma_{18}{ }^{1}$ & -0.0100 & -0.8961 & 0.3705 \\
\hline$\gamma_{19}{ }^{1}$ & -0.0208 & -1.6550 & 0.0984 \\
\hline$\underline{\gamma}_{20}{ }^{1}$ & 0.0041 & 0.2765 & 0.7822 \\
\hline$\gamma_{21}{ }^{1}$ & -0.0145 & -0.9105 & 0.3629 \\
\hline$\gamma_{22}{ }^{1}$ & -0.0134 & -2.0481 & 0.0409 \\
\hline$\gamma_{23}{ }^{1}$ & -0.0177 & -2.7189 & 0.0067 \\
\hline$\gamma_{24}{ }^{1}$ & -0.0111 & -2.2871 & 0.0225 \\
\hline$\gamma_{25}{ }^{1}$ & -0.0269 & -1.9762 & 0.0485 \\
\hline$\gamma_{26}{ }^{1}$ & -0.0117 & -0.5124 & 0.6085 \\
\hline$\gamma_{27}^{1}$ & 0.0007 & 0.1118 & 0.9110 \\
\hline$\gamma_{28}{ }^{1}$ & -0.0124 & -0.6601 & 0.5094 \\
\hline$\gamma_{29}{ }^{1}$ & -0.0168 & -0.7737 & 0.4394 \\
\hline$\gamma_{30}^{1}$ & -0.0223 & -1.7190 & 0.0861 \\
\hline$\gamma_{31}^{1}$ & -0.0083 & -0.2970 & 0.7666 \\
\hline$\gamma_{32}{ }^{1}$ & 0.0255 & 1.0123 & 0.3118 \\
\hline$\gamma_{33}{ }^{1}$ & -0.0125 & -0.6898 & 0.4905 \\
\hline$\gamma_{34}{ }^{1}$ & -0.0346 & -1.8678 & 0.0622 \\
\hline$\gamma_{35}{ }^{1}$ & -0.0245 & -2.5727 & 0.0103 \\
\hline$\gamma_{36}^{1}$ & -0.0058 & -0.8830 & 0.3776 \\
\hline$\gamma_{37}{ }^{1}$ & -0.0060 & -0.4000 & 0.6893 \\
\hline$\gamma_{38}^{1}$ & 0.0055 & 0.4044 & 0.6861 \\
\hline$\gamma_{39}{ }^{1}$ & 0.0058 & 0.2612 & 0.7940 \\
\hline$\gamma_{40}^{1}$ & -0.0076 & -0.7430 & 0.4578 \\
\hline$\gamma_{41}^{1}$ & 0.0002 & 0.0279 & 0.9778 \\
\hline$\gamma_{42}{ }^{1}$ & 0.0030 & 0.3713 & 0.7105 \\
\hline$\gamma_{43}^{1}$ & -0.0263 & -2.2566 & 0.0244 \\
\hline$\gamma_{44}{ }^{1}$ & -0.0060 & -0.7180 & 0.4730 \\
\hline$\gamma_{45}{ }^{1}$ & -0.0250 & -1.3810 & 0.1677 \\
\hline$\gamma_{46}^{1}$ & -0.0253 & -1.8144 & 0.0701 \\
\hline$\gamma_{47}^{1}$ & -0.0394 & -2.2721 & 0.0234 \\
\hline
\end{tabular}

Adjusted R-squared $\quad 0.9886$ Standard error of regression $\quad 0.0113$

\begin{tabular}{|c|c|c|c|}
\hline & Coefficient & $\mathrm{t}$-Statistic & P-value \\
\hline$\zeta_{1}{ }^{1}$ & \begin{tabular}{|l|}
0.7109 \\
\end{tabular} & 5.3842 & 0.0000 \\
\hline$\zeta_{2}^{1}$ & 0.7168 & 5.2351 & 0.0000 \\
\hline$\zeta_{3}{ }^{1}$ & 0.7141 & 5.7988 & 0.0000 \\
\hline$\zeta_{4}{ }^{1}$ & 0.7488 & 6.3943 & 0.0000 \\
\hline$\zeta_{5}{ }^{1}$ & 0.7529 & 6.1722 & 0.0000 \\
\hline$\zeta_{6}{ }^{1}$ & 0.7728 & 6.0362 & 0.0000 \\
\hline$\zeta_{7}^{1}$ & 0.7748 & 6.0904 & 0.0000 \\
\hline$\zeta_{8}{ }^{1}$ & 0.8944 & 8.4684 & 0.0000 \\
\hline$\zeta_{9}{ }^{1}$ & 0.9091 & 9.3269 & 0.0000 \\
\hline$\zeta_{10}^{1}$ & 0.8151 & 6.5498 & 0.0000 \\
\hline$\zeta_{11}{ }^{1}$ & 0.8176 & 8.3965 & 0.0000 \\
\hline$\zeta_{12}{ }^{1}$ & 0.6637 & 4.7788 & 0.0000 \\
\hline$\zeta_{13}{ }^{1}$ & 0.6169 & 2.7586 & 0.0060 \\
\hline$\zeta_{14}{ }^{1}$ & 0.7210 & 5.3719 & 0.0000 \\
\hline$\zeta_{15}{ }^{1}$ & 0.8229 & 7.4197 & 0.0000 \\
\hline$\zeta_{16}{ }^{1}$ & 0.8941 & 9.7208 & 0.0000 \\
\hline$\zeta_{17}{ }^{1}$ & 0.7652 & 5.8206 & 0.0000 \\
\hline$\zeta_{18}{ }^{1}$ & 0.8593 & 5.5887 & 0.0000 \\
\hline$\zeta_{19}{ }^{1}$ & 0.9162 & 6.5050 & 0.0000 \\
\hline$\zeta_{20}{ }^{1}$ & 0.8117 & 4.5497 & 0.0000 \\
\hline$\zeta_{21}^{1}$ & 0.8737 & 6.1900 & 0.0000 \\
\hline$\zeta_{22}^{1}$ & 0.9406 & 11.7914 & 0.0000 \\
\hline$\zeta_{23}{ }^{1}$ & 0.8450 & 7.5270 & 0.0000 \\
\hline$\zeta_{24}^{1}$ & 0.7880 & 7.1729 & 0.0000 \\
\hline$\zeta_{25}{ }^{1}$ & 0.8392 & 8.0222 & 0.0000 \\
\hline$\zeta_{26}^{1}$ & 0.8387 & 9.4564 & 0.0000 \\
\hline$\zeta_{27}{ }^{1}$ & 0.8553 & 14.6508 & 0.0000 \\
\hline$\zeta_{28}^{1}$ & 0.8386 & 11.4942 & 0.0000 \\
\hline$\zeta_{29}^{1}$ & 0.8722 & 8.1423 & 0.0000 \\
\hline$\zeta_{30}^{1}$ & 0.8810 & 7.2060 & 0.0000 \\
\hline$\zeta_{31}^{1}$ & 0.7961 & 4.2720 & 0.0000 \\
\hline$\zeta_{32}{ }^{1}$ & 0.6917 & 3.2832 & 0.0011 \\
\hline$\zeta_{33}^{1}$ & 0.8083 & 9.4996 & 0.0000 \\
\hline$\zeta_{34}^{1}$ & 0.8894 & 11.1853 & 0.0000 \\
\hline$\zeta_{35}^{1}$ & 0.9162 & 7.7331 & 0.0000 \\
\hline$\zeta_{36}^{1}$ & 0.7406 & 3.6184 & 0.0003 \\
\hline$\zeta_{37}{ }^{1}$ & 0.8052 & 4.8020 & 0.0000 \\
\hline$\zeta_{38}^{1}$ & 0.6861 & 3.7837 & 0.0002 \\
\hline$\zeta_{39}{ }^{1}$ & 0.7839 & 4.7644 & 0.0000 \\
\hline$\zeta_{40}^{1}$ & 0.7812 & 5.1399 & 0.0000 \\
\hline$\zeta_{41}{ }^{1}$ & 0.7540 & 5.5947 & 0.0000 \\
\hline$\zeta_{42}^{1}$ & 0.7837 & 6.6040 & 0.0000 \\
\hline$\zeta_{43}{ }^{1}$ & 0.8385 & 6.9170 & 0.0000 \\
\hline$\zeta_{44}^{1}$ & 0.8644 & 5.9672 & 0.0000 \\
\hline$\zeta_{45}^{1}$ & 0.8107 & 6.4626 & 0.0000 \\
\hline$\zeta_{46}{ }^{1}$ & 0.8703 & 7.0120 & 0.0000 \\
\hline$\zeta_{47}{ }^{1}$ & 0.8108 & 7.5980 & 0.0000 \\
\hline
\end{tabular}

Log likelihood $\quad 2527.284$ Schwarz criterion $\quad-5.1383$ 